\title{
The correlation between friction coefficient and areal topography parameters for AISI 304 steel sliding against AISI 52100 steel
}

\author{
Deepak K. PRAJAPATI ${ }^{*}$, Mayank TIWARI \\ Department of Mechanical Engineering, Indian Institute of Technology, Patna 801103, India \\ Received: 13 February 2019 / Revised: 21 May 2019 / Accepted: 14 August 2019 \\ (C) The author(s) 2019.
}

\begin{abstract}
Dry wear experiments provide an insight detail on how severely contacting surfaces change under unlubricated sliding condition. The theory of dry sliding wear is used for understanding mixed-lubrication regime in which asperity interactions play a significant role in controlling of the friction coefficient $(f)$. The purpose of this work is to study the tribological behavior of AISI 304 steel in contact with AISI 52100 steel during wear. Both materials are used in rolling element bearings commanly. Experiments are carried out using a pin-on-disc tribometer under dry friction condition. The areal (three dimensional, 3D) topography parameters are measured using a 3D white light interferometer (WLI) with a 10× objective. After wear tests, wear mechanisms are analyzed utilizing scanning electron microscope (SEM). Factorial design with custom response surface design (C-RSD) is used to study the mutual effect of load and speed on response variables such as $f$ and topography parameters. It is observed that the root mean square roughness $\left(S_{q}\right)$ decreases with an increase in sliding time. Within the range of sliding time, $S_{q}$ decreases with an increase in the normal load. Within the range of sliding speed and normal load, it is found that $S_{q}$, mean summit curvature $\left(S_{\mathrm{sc}}\right)$, and root mean square slope $\left(S_{d q}\right)$ are positively correlated with $f$. Whereas, negative correlation is found between $f$ and correlation length $\left(S_{\mathrm{al}}\right)$, mean summit radius $(R)$, and core roughness depth $\left(S_{k}\right)$.
\end{abstract}

Keywords: friction coefficient $(f)$; areal topography parameters; factorial design; non-contact optical profiler; scanning electron microscope (SEM)

\section{Introduction}

Severe asperity-to-asperity contacts cause serious failure in high power density machines (power throughput /weight) such as wind turbines, electric drive trains, high power transmission machines, off-highway vehicles (OHV's), and paper machines [1-3]. Nonconformal concentrated tribological contacts are usually subjected to rolling/sliding or pure sliding motion causes asperity removal from the mating surfaces and the process is known as 'wear' resulting in significant loss of material. It is generally expected to run tribological components in elastohydrodynamic lubrication regime, but what is achieved is boundary and mixed-lubrication regimes which are the primary cause for the breakdown of high power density machines [1-3]. Dynamic friction arises due to shearing of asperities and varies according to the shear strength of the contacting materials, the normal load, hardness of material, and composite surface roughness. Improvement in sliding friction depends on various factors but most importantly it relies on surface topography [1-3]. Slight improvement in friction and wear may increase the performance which can be quantified in terms of the reliability and life of components $[4,5]$. The pin-on-disc wear test rig is one of most common configurations and used for simulating sliding part of the non-conformal concentrated contacts subjected to rolling/sliding motion. To simulate the sliding part of non-conformal concentrated contacts, recommended

* Corresponding author: Deepak K. PRAJAPATI, E-mail: deepak.pme14@iitp.ac.in 


\begin{tabular}{|c|c|c|c|}
\hline \multicolumn{4}{|c|}{ Nomenclature } \\
\hline$F_{\mathrm{N}}$ & Applied normal load (N) & $S_{\text {sk }}$ & Skewness \\
\hline$r_{\mathrm{o}}$ & Disc radius (mm) & $S_{\mathrm{ku}}$ & Kurtosis \\
\hline$r_{i}$ & Wear track radius (mmm) & $S_{k}$ & Core roughness $(\mu \mathrm{m})$ \\
\hline$N_{\text {rot }}$ & Rotational speed (rpm) & $f$ & Friction coefficient \\
\hline$S_{q}$ & Root mean square $(\mathrm{RMS})$ roughness $(\mu \mathrm{m})$ & $L$ & Load $(\mathrm{N})$ \\
\hline$S_{d q}$ & RMS slope & $V$ & Speed (rpm) \\
\hline$S_{\mathrm{al}}$ & Autocorrelation length $(\mu \mathrm{m})$ & $A_{\text {nom }}$ & Nominal area $\left(\mathrm{mm}^{2}\right)$ \\
\hline$S_{\mathrm{sc}}$ & Mean summit curvature $\left(\mu \mathrm{m}^{-1}\right)$ & $r_{i}$ & Wear track radius $(\mathrm{mm})$ \\
\hline
\end{tabular}

wear configuration in the ASTM G99-95a (reapproved 2000) standard is a spherical ball (or radius-end pin) against a flat disc [6]. The advantage of a spherical ball or radius-end pin is that it reduces the possibility of misalignment and reproducible alignment between ball (or radius-end pin) and the counter disc surfaces can be easily obtained [7]. AISI 304 (304SS) is the most widely used stainless steel grade in rolling element bearings, wind turbines, and gearboxes, etc. Previously, the tribological behavior of AISI 304 steel has been widely attempted [8-14]. The reduction in abrasive wear has been studied by Alias et al. [8]. They showed improvement in hardness of AISI 304 steel resulting inreduction in abrasive wear when boronizing temperature increased from 850 to $950{ }^{\circ} \mathrm{C}$. The effect of relative humidity and load on austenitic steel (AISI 304) characterized by two different grain sizes ( 2.5 and $40 \mu \mathrm{m}$ ) have been reported by Bregliozzi et al. [9]. They found higher value friction at higher relative humidity for the same loading conditions. The effects of microstructure on EN-8 and AISI 304 have been reported by Kumar and Mukhopadhyay [10]. They found minimum wear on normalized AISI 304 samples, whereas, higher friction was found for oilquenched AISI 304 steel samples. The effect of grain size and load on heat treated AISI 304 has been discussed by Nafar et al. [11]. They concluded that there is better wear resistance under normal loads of 10 and $20 \mathrm{~N}$ with ultra-fine grained steel $(650 \mathrm{~nm}$ grain size), whereas, at a normal load of $30 \mathrm{~N}$, weak wear resistance has been found as compared to the steel with larger grain size ( 3 and $12 \mathrm{~lm}$ ). The sliding behavior of surface mechanical attrition (SMA) treated AISI 304 steel has been reported by Sun [12]. He concluded that SMA treatment does not affect tribological behavior significantly under dry conditions. However, under oil-lubricate conditions, better wear resistance has been found for the wide range of contact loads. Sun and Bailey [13] investigated the tribocorrosion behavior of SMA treated AISI 304 by performing tribocorrosion tests in $0.9 \% \mathrm{NaCl}$ solution under different operating conditions. They reported that SMA treatment is effective in reducing material removal by 2 to 4 times under all combined sliding wear and electrochemical conditions due to surface and sub-surface hardening effect induced by SMA process. Improved tribological properties have been found for low-temperature plasma carburizing (LTPC) treated AISI 304 during pin-on-disc wear test [14]. Previously, 2D parameters such as root mean square roughness $\left(R_{q}\right)$, skewness $\left(R_{\mathrm{sk}}\right)$, and kurtosis $\left(R_{\mathrm{ku}}\right)$ have been used for characterizing the worn surfaces. Recently, research has been directed towards the use of areal (3D) topography parameters for characterization of unworn/worn rough surfaces. The areal (3D) topography parameters have many advantages in comparison to the profile (2D) roughness parameters [15-17]. In past, few experimental studies have been reported on the evolution of the areal (3D) topography parameters during wear [18-21]. Recently, it has been shown from numerical simulation that areal topography parameters change significantly during the wear and a good match between experimental and numerical results has been obtained [22].

From the above-outlined literature, few studies have been reported on the evolution of the topography parameters under dry sliding condition [8-14]. Dry sliding contact theory is used to get an insight on mixed-lubrication regime which is the primary basis for failure of many tribological components [23, 24]. 
For the better understanding of asperity based failure mechanisms, study of the evolution of topography parameters under dry sliding is important which can provide new insight on how asperity characteristics will evolve under mixed-lubrication regime.

The aim of this work is to study the evolution of topography parameters and their correlation with friction coefficient $f$ for AISI 304 steel under dry friction condition. Extensive experiments are performed to see the effect of load and speed on areal topography parameters. Variation of areal topography parameters with an increase in sliding time for different load is also discussed. The surface roughness at the different sliding time is measured using a 3D WLI non-contact optical profiler (Rtec Instruments, USA). Scanning electron microscope (SEM) under secondary electron emission mode is used for studying the surface morphology. The important areal (3D) topography parameters used in this study are briefly described in Appendix A.

\section{Experimental details}

\subsection{Sample preparation}

Pin samples having $6 \mathrm{~mm}$ diameter and $25 \mathrm{~mm}$ length are cut from AISI 304 steel bars. Hemispherical shape on pin samples is produced using turning. Silicon carbide grinding papers (Grade: 600, 800, and 1,000) used to finish pin samples. The sample disc (AISI 52100) having $50 \mathrm{~mm}$ diameter and $10 \mathrm{~mm}$ thickness is ground up to $S_{q}$ less than $0.2 \mu \mathrm{m}$. The hardness of AISI 304 and AISI 52100 is measured using Vickers hardness tester (Zwick, USA) and found to be 325 and $690 \mathrm{HV}$, respectively.

\subsection{Experimental procedure}

The experiments are carried out using a pin-on-disc (Rtec Instruments, USA) tribometer under dry friction condition. Figure 1 shows the schematic representation of the pin-on-disc configuration. In this work, short duration tests at $20 \mathrm{~N}$ normal load and $500 \mathrm{rpm}$ rotational speed are performed for $2 \mathrm{~min}$ on eleven hemispherical pin surfaces (P1-P11). The test conditions for short duration tests are shown in Table 1. The objective behind performing short duration tests is to achieve a flat pin surface which can be easily

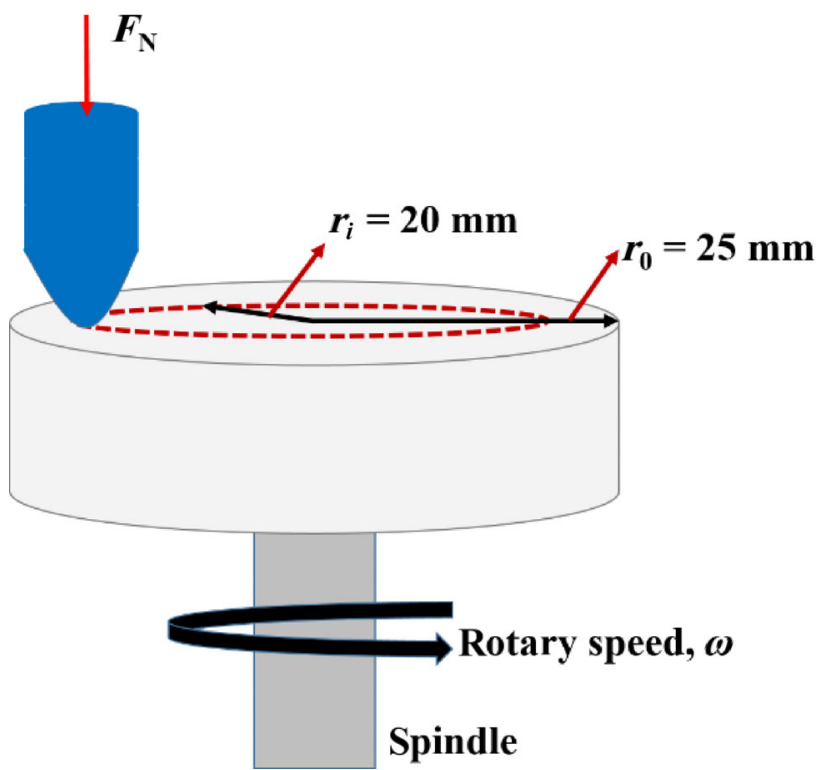

Fig. 1 Schematic of pin-on-disc configuration.

Table 1 Experimental conditions for short duration tests.

\begin{tabular}{lc}
\multicolumn{1}{c}{ Parameter } & Value \\
\hline Normal load, $F_{\mathrm{N}}$ & $20 \mathrm{~N}$ \\
Initial Hertzian stress, $p_{\text {max }}$ & $1.8 \mathrm{GPa}$ \\
Initial mean contact pressure, $p_{\text {mean }}$ & $1.2 \mathrm{GPa}$ \\
Contact radius, $a$ & $70 \mu \mathrm{m}$ \\
Wear track radius, $r_{i}$ & $20 \mathrm{~mm}$ \\
Disc rotating speed, $N_{\text {rot }}$ & $500 \mathrm{rpm}$ \\
Sliding velocity & $1.04 \mathrm{~m} / \mathrm{s}$ \\
Relative humidity, RH & $61 \%$ \\
Ambient temperature & $25{ }^{\circ} \mathrm{C}$ \\
Test run time & $2 \mathrm{~min}$ \\
Disc radius, $r_{0}$ & $25 \mathrm{~mm}$ \\
Pin diameter & $6 \mathrm{~mm}$ \\
Contact type & Point-on-flat \\
\hline
\end{tabular}

measured using non-contact optical profiler. After short duration test, topographies of all flat pins (S1-S11) are measured using a 3D WLI non-contact optical profiler with $10 \times$ objective. These flat pins (S1-S11) are further used to perform friction tests at different load and speed conditions. Test conditions for performing friction tests are shown in Table 2 . The schematic of overall test procedure followed in this work is shown in Fig. 2. Wear debris generated during the experiment are not removed from the 
Table 2 Experimental conditions for friction tests.

\begin{tabular}{lc}
\hline \multicolumn{1}{c}{ Parameter } & Value \\
\hline Normal load, $F_{\mathrm{N}}$ & $20-40 \mathrm{~N}$ \\
Mean contact pressure, $p_{\text {mean }}$ & $14.38-28.78 \mathrm{MPa}$ \\
Contact radius, $a$ & $649 \mu \mathrm{m}$ \\
Wear track radius, $r_{i}$ & $20 \mathrm{~mm}$ \\
Disc rotating speed, $N_{\text {rot }}$ & $200-400 \mathrm{rpm}$ \\
Relative humidity, $\mathrm{RH}$ & $61 \%$ \\
Ambient temperature & $25{ }^{\circ} \mathrm{C}$ \\
Test run time & $5 \mathrm{~min}$ for each test \\
Sliding velocity & $0.41-0.83 \mathrm{~m} / \mathrm{s}$ \\
Disc radius, $r_{0}$ & $25 \mathrm{~mm}$ \\
Contact type & Flat-on-flat \\
\hline
\end{tabular}

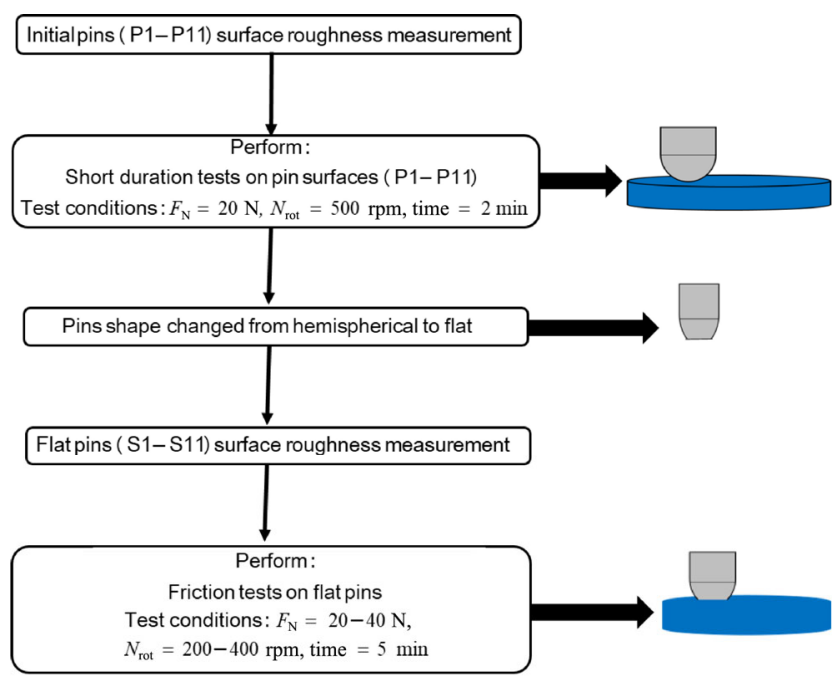

Fig. 2 Schematic of overall test procedure.

wear track. However, pin samples and disc wear track are cleaned using acetone and dried after each experiment. All wear experiments are performed in the ambient environment $\left(25^{\circ} \mathrm{C}, 61 \%\right.$ relative humidity $)$. Surface topographies of pin and disc surfaces at different load stages are measured using a WLI non-contact optical profiler with $10 \times$ objective. The measured surface contains a surface area of $1.9 \mathrm{~mm} \times$ $1.16 \mathrm{~mm}(960 \times 600$ sampling points). Figures 3(a)-3(d) represent the surface map of some unworn (before flattening) pin samples. The $S_{q}$ of unworn pin samples is found within the range of $8.25 \pm 0.25 \mu \mathrm{m}$. Figure 4 represents the surface maps of the unworn disc. The $S_{q}$ of the disc is $0.15 \mu \mathrm{m}$.
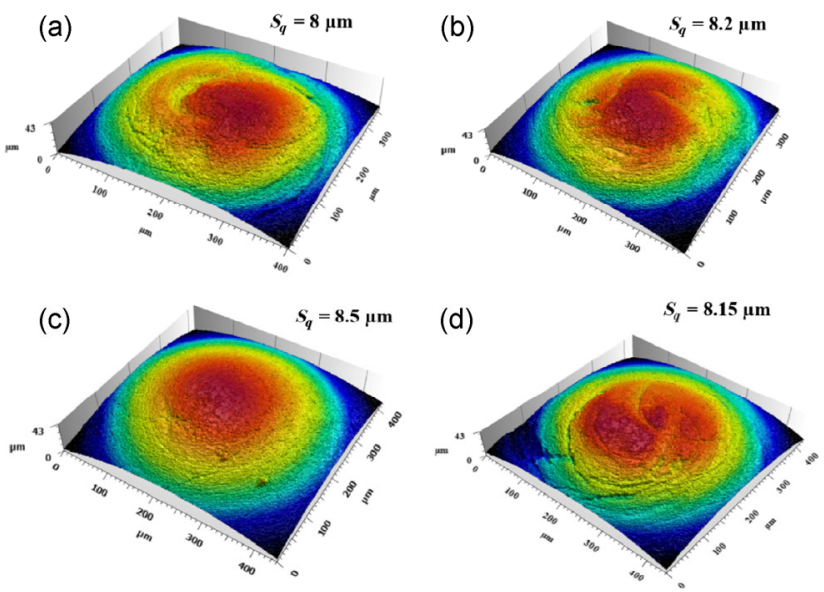

Fig. 3 Surface maps of four unworn hemispherical pin surfaces (a) pin surface 1, P1, (b) pin surface 2, P2, (c) pin surface 3, P3, and (d) pin surface $4, \mathrm{P} 4$.

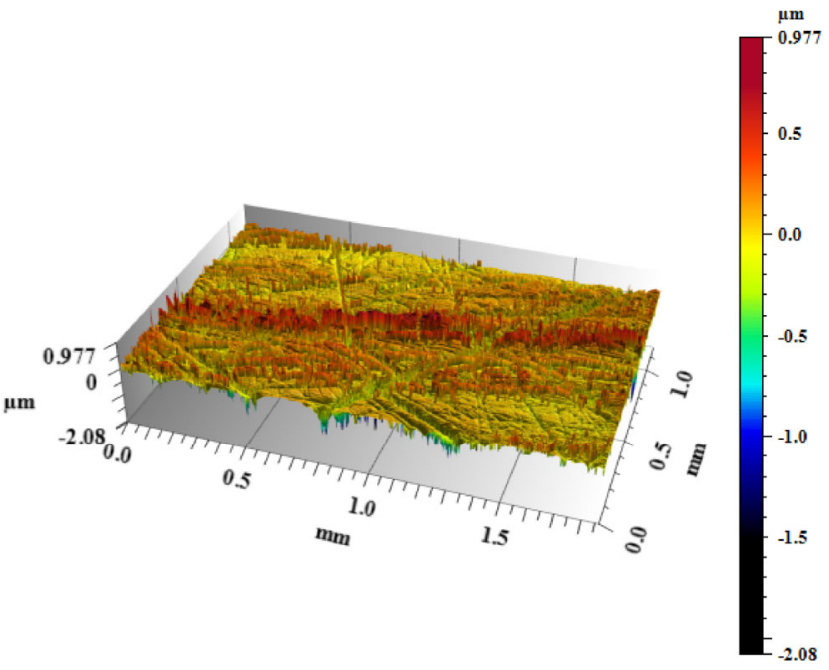

Fig. 4 Surface map of unworn disc (AISI 52100 steel).

\section{Results and discussion}

\subsection{Results of short duration tests}

The results obtained from the short duration tests are presented in Figs. 5 and 6. The short duration test is performed at low load $(20 \mathrm{~N})$ and high speed (500 rpm) conditions for $2 \mathrm{~min}$ of sliding time. At lower load and higher speed conditions, contacting asperities are removed very quickly from contacting bodies resulting in flattened rough surfaces $[25,26]$. Figure 5 shows the variation of the $f$ with sliding time for eleven pin surfaces, S1-S11. It can be seen from Fig. 5 that for all pin surfaces except S2 and S11, the variation of the friction coefficient with sliding time 


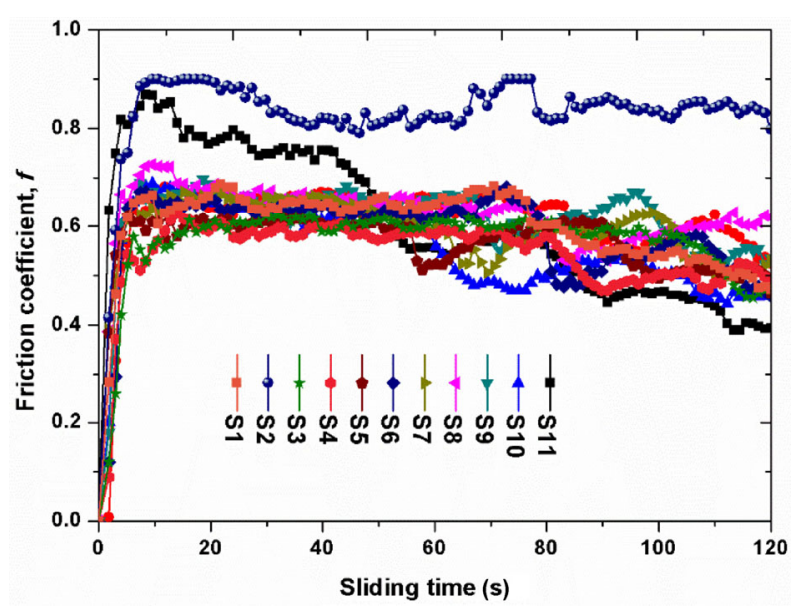

Fig. 5 Variation of $\mathrm{f}$ with sliding time for pin samples, $\mathrm{S} 1-\mathrm{S} 11$ $\left(F_{\mathrm{N}}=20 \mathrm{~N}, N_{\text {rot }}=500 \mathrm{rpm}\right.$, sliding time $\left.=2 \mathrm{~min}\right)$.

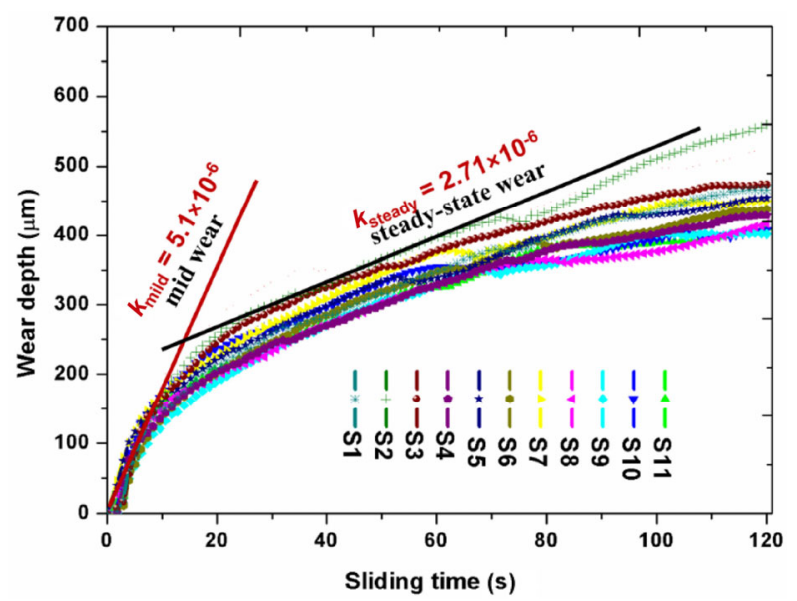

Fig. 6 Variation of wear depth with sliding time for pin samples, $\mathrm{S} 1-\mathrm{S} 11\left(F_{\mathrm{N}}=200 \mathrm{~N}, N_{\text {rot }}=500 \mathrm{rpm}\right.$, sliding time $\left.=2 \mathrm{~min}\right)$. is almost the same. As illustrated in Fig. 5, the $f$ increases first with an increase in sliding time, reaches its maximum value and become almost constant for further increase in sliding time. The state at which the $f$ increases from 0 to maximum value is the transient state of the friction, and the state at which the $f$ variation with sliding time is almost constant is the steady state of the friction [21-23]. For S2 and S11, the maximum value (0.9) of the friction occurs at sliding time of $10 \mathrm{~s}$ which is slightly higher than the maximum value of friction for other pin samples (S1, S3-S10). However, the trend on the variation of $f$ with sliding time for S2 and S11 is nearly the same as observed for other pin samples (S1, S3-S10). Figure 6 represents the variation of wear depth with an increase in sliding time. It can be seen from Fig. 6 that wear depth increases with an increase in sliding time. As illustrated in Fig. 6, the variation of wear depth with sliding time is almost the same for all pin surfaces (S1-S11). It was shown in Ref. [26] that during running-in, wear depth increases with an increase in sliding time or number of cycles. Two distinct wear states can also be seen from Fig. 6. It can be inferred from Figs. 5 and 6 that basically short duration test is an initial running-in process during which conformity between contating surface increases. Figures $7(\mathrm{a})-7(\mathrm{f})$ represent the surface maps of six pin surfaces after short duration tests. It can be seen from Fig. 7 that removal of asperity peaks are nearly (a)

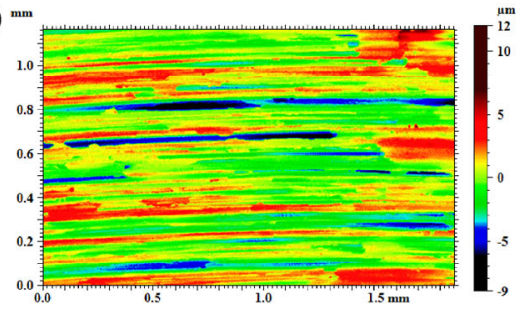

(b)

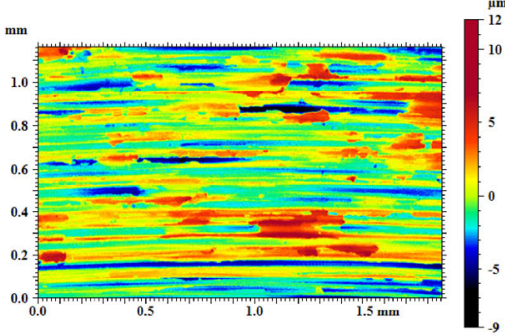

(c)

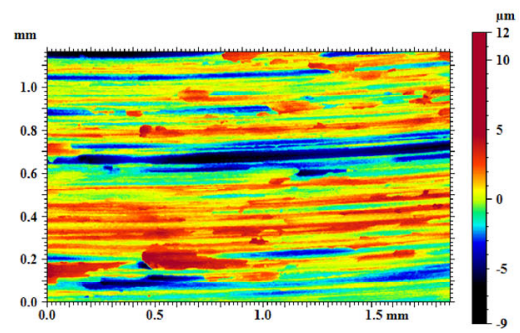

(d)

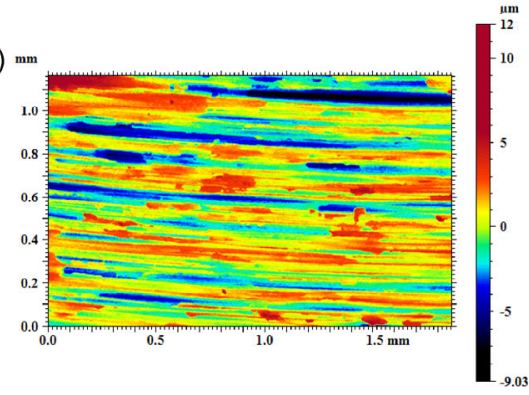

(e) ${ }^{m r}$

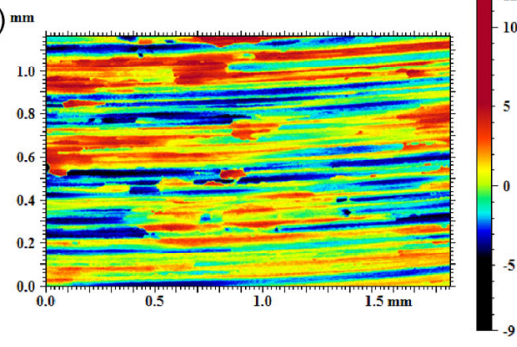

(f) $m$

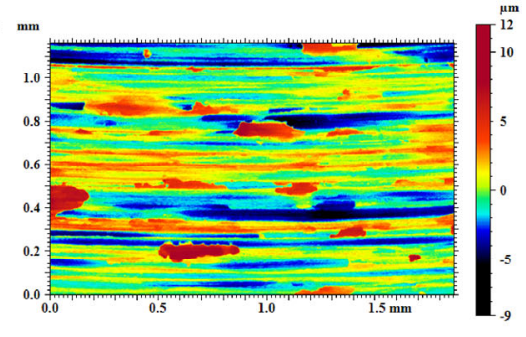

Fig. 7 Surface maps of pin surfaces after short duration tests: (a) S1, (b) S2, (c) S3, (d) S4, (e) S5, and (f) S6. 
the same in all surface maps (Figs. 7(a)-7(f)). Table 3 represents calculated topography parameters $\left(S_{q}, S_{\mathrm{sk}}\right.$, and $S_{\mathrm{ku}}$ ), scar radius, and sliding distance for all pin surfaces (S1-S11) after short duration tests. It can be seen from Table 3 that $S_{q}$ of all measured pin surfaces lies in the range of $2.4 \pm 0.4 \mu \mathrm{m}$. $S_{\mathrm{sk}}$ and $S_{\mathrm{ku}}$ for measured pin surfaces are found in the range of $-0.356 \pm 0.05$ and $3.9 \pm 0.9$, respectively (Table 3). The scar radius is found within range of $679 \pm 19 \%$, as shown in Table 3.

Table 3 Calculated roughness parameters after short test for pin surfaces $(\mathrm{S} 1-\mathrm{S} 11)\left(F_{\mathrm{N}}=200 \mathrm{~N}, N_{\mathrm{rot}}=500 \mathrm{rpm}\right.$, sliding time $\left.=2 \mathrm{~min}\right)$.

\begin{tabular}{cccccc}
\hline $\begin{array}{c}\text { Sample } \\
\text { No. }\end{array}$ & $\begin{array}{c}S_{q} \\
(\mu \mathrm{m})\end{array}$ & $S_{\mathrm{sk}}$ & $S_{\mathrm{ku}}$ & $\begin{array}{c}\text { Scar } \\
\text { radius } \\
(\mathrm{mm})\end{array}$ & $\begin{array}{c}\text { Sliding } \\
\text { distance } \\
(\mathrm{m})\end{array}$ \\
\hline S1 & 2.4 & -0.398 & 3.2 & 0.649 & 125 \\
S2 & 2.2 & -0.353 & 2.9 & 0.548 & 125 \\
S3 & 2.0 & -0.411 & 3.5 & 0.666 & 125 \\
S4 & 2.1 & -0.361 & 3.2 & 0.624 & 125 \\
S5 & 2.4 & -0.378 & 4.8 & 0.809 & 125 \\
S6 & 2.3 & -0.401 & 3.8 & 0.767 & 125 \\
S7 & 2.1 & -0.375 & 3.5 & 0.645 & 125 \\
S8 & 2.8 & -0.302 & 3.1 & 0.743 & 125 \\
S9 & 2.4 & -0.341 & 3.0 & 0.643 & 125 \\
S10 & 2.1 & -0.383 & 3.4 & 0.661 & 125 \\
S11 & 2.1 & -0.405 & 3.7 & 0.712 & 125 \\
\hline
\end{tabular}

In this work, it is assumed that negligible wear in comparison to pin surface (AISI 304) occurs on the disc surface (AISI 52100), which can also be verified from Figs. 8 and 9. Figure 8 shows the optical micrographs of six pin surfaces (S1-S6) after short duration tests. It can be seen from Fig. 8 that average pin scar area is $1.44 \mathrm{~mm}^{2}$, whereas, valley area of disc within sliding track is $0.147 \mathrm{~mm}^{2}$ (Fig. 9), which is far less than pin scar area. So, it can be inferred that very less material is removed from the disc surface in comparison to pin surfaces. From Section 3.2, topography parameters calculated from pin (AISI 304) surface measurement are reported.

\subsection{Variation of topography parameters with sliding time for friction tests}

It has been shown in Refs. $[22,27]$ that topography
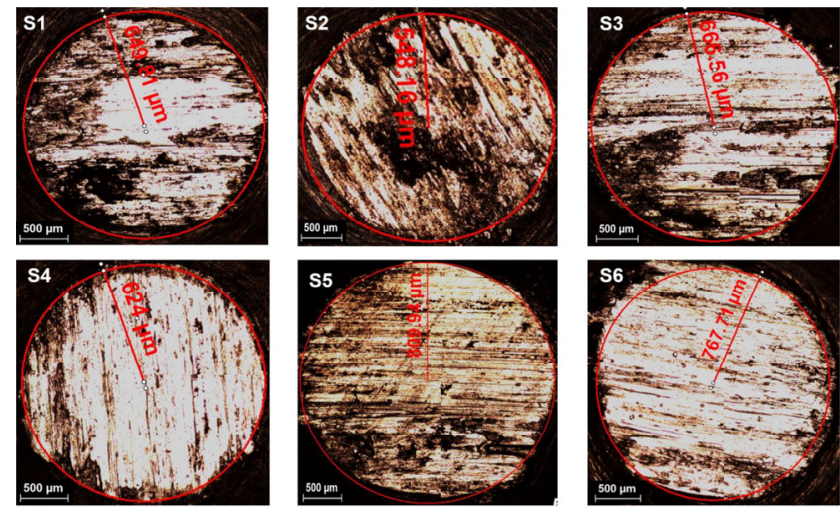

Fig. 8 Optical micrographs of six pin surfaces (S1-S6) after short duration tests (scar radius is indicated with red color on each micrographs).
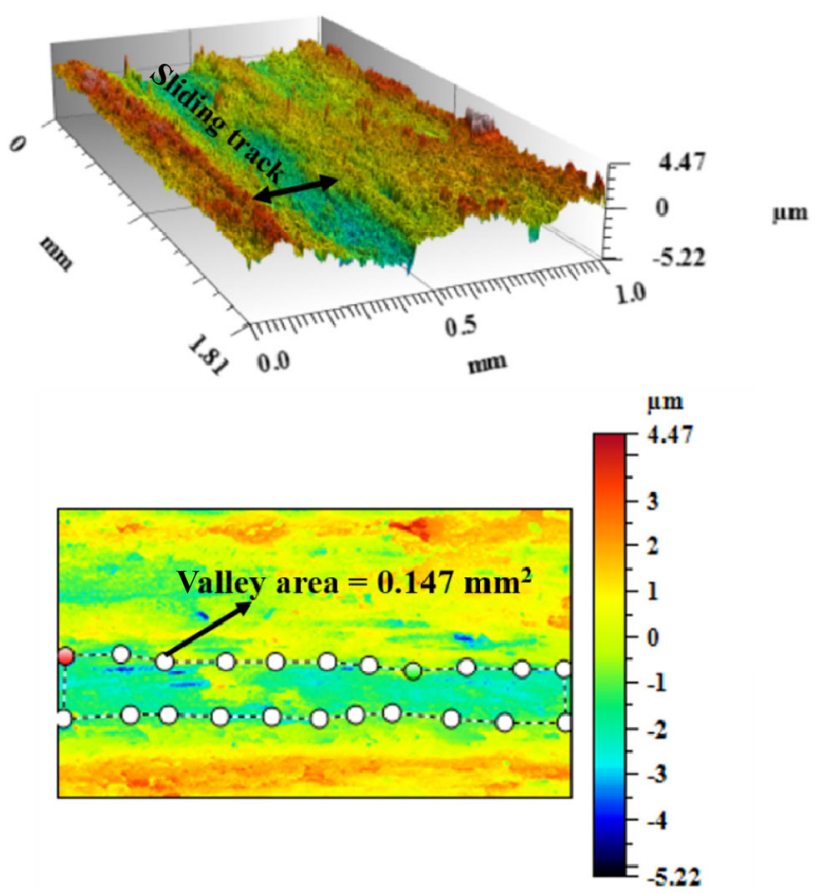

Fig. 9 Surface map and calculated valley area of AISI 52100 disc after short duration test.

parameters vary significantly during wear. However, in most of the papers, only $R_{q}, R_{\mathrm{sk}}, R_{\mathrm{ku}}$ or its $3 \mathrm{D}$ equivalent topography parameters have been reported. Recently, Lenart et al. [20] showed that there are other topography parameters which also vary significantly during fretting wear. Sedlaček et al. [28] showed a correlation between skewness, kurtosis and tribological behavior of contacting surfaces. In past, the tribological behavior of contacting bodies has also been analyzed by using bearing area curve (BAC) [21, 29]. Here 
the evolution of important areal (3D) topography parameters during wear are discussed in detail. Figures 10-12 represent the variation of areal topography parameters with sliding time. The test conditions are shown in each figures captions. The topography of the pin surface is measured using a 3D WLI profiler at an interval of 1 min of sliding time. It can be seen from Fig. 10 that $S_{q}$ decreases with an increase in sliding time. As sliding time increases, more asperity peaks remove from the pin surface resulting in the decrease of $S_{q}$. More asperity removal is expected from the pin surfaces due to less hardness in comparison to disc material (AISI 52100). As illustrated in Fig. 10, $S_{q}$ slightly increases at $3 \mathrm{~min}$ of sliding time. This happens due to entrapment of

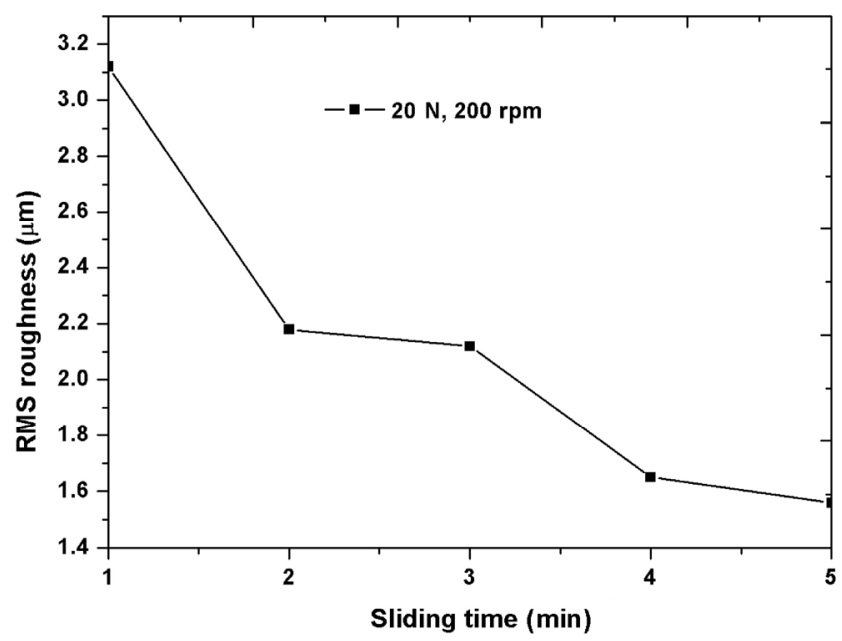

Fig. 10 Variation of RMS roughness $\left(S_{q}\right)$ with sliding time.

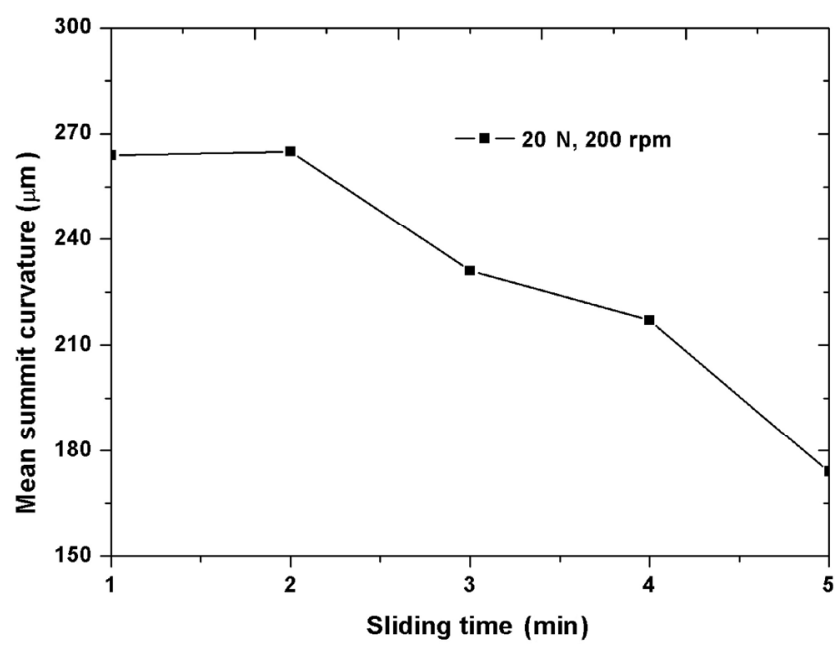

Fig. 11 Variation of mean summit curvature $\left(S_{\mathrm{sc}}\right)$ with sliding time.

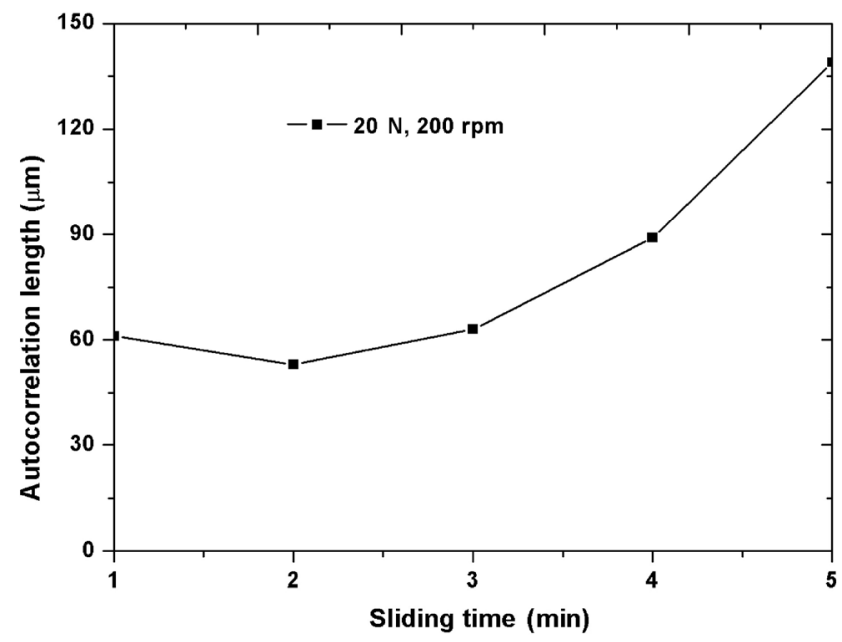

Fig. 12 Variation of autocorrelation length $\left(S_{\mathrm{al}}\right)$ with sliding time.

asperity within the contact zone resulting in three body abrasion ultimately increasing the surface roughness. Figure 11 shows the variation of $S_{\mathrm{sc}}$ with an increase in sliding time. It can be seen that $S_{\mathrm{sc}}$ decreases with an increase in sliding time. This happens due to the removal of asperity peaks during wear. As the asperity peaks remove from the contacting bodies, roughness peaks become flattened resulting in the decrease of $S_{\mathrm{sc}}$. It is known that the mean summit radius of curvature $\left(R \propto 1 / S_{\mathrm{sc}}\right)$ is inversely related to $S_{\mathrm{sc}}$. Higher mean summit curvature indicates sharp roughness peaks and lower mean summit curvature represents flattened roughness peaks. It can be inferred from Fig. 11 that roughness peaks smoothness increases with an increase in sliding time. Figure 12 shows the variation of $S_{\text {al }}$ with an increase in sliding time. The $S_{\text {al }}$ is defined as the length at which the autocorrelation function decay up to $10 \%$ of its original value at the origin in $x$ - or $y$-directions. It is a parameter which relates roughness heights to the spatial dimension of the surface. As illustrated in Fig. 12, the $S_{\text {al }}$ first slightly decreases ( within 1 to 2 min of sliding time) and then increases with an increase in sliding time. The reason is flatness of the roughness peaks which increases with further an increase in sliding time ( 2 to 5 min of sliding time). It can also be seen from Fig. 12 that autocorrelation length increases very sharply when sliding time increases from 4 to $5 \mathrm{~min}$. This is due to sufficient removal of asperity peaks from the pin surface till 
4 min of sliding time.

Figures 13(a)-13(e) represent the surface map of AISI 304 pin surfaces with an increase in sliding time. The color map is also shown at right side of each figures (Figs. 13(a)-13(e)). In colormap, red color indicates the roughness pekas above the mean plane, whereas, blue represents the valley depth, and yellow color represents value of roughness peaks very close to zero (i.e., mean plane of the surface). As illustrated in Figs. 13(a)-13(e), roughness peak heights decrease smaller (red color in surface maps decreases with an increase in sliding time) with an increase in sliding time. It can also be seen from Fig. 13(d) that sufficient roughness peaks are removed from the pin surface till $4 \mathrm{~min}$ of sliding time. Further increase in sliding time from 4 to $5 \mathrm{~min}$ resulting in some asperity peaks removal from the pin surface (Fig. 13(e)), however, no significant reduction in asperity peaks is observed. It can be inferred from Figs. 13(a) to 13(e), flatness of the pin surface increases with an increase in sliding time, resulting in an increase in $S_{\text {al. }}$. Also, for 2 min of sliding time, the appearance of distributed asperities in Fig. 13(b) indicates the presence of shorter wavelength components.

\subsection{Effect of load on topography parameters}

It has been mentioned in Refs. $[30,31]$ that $f$ increases with an increase in load. In dry contact, at lower load, oxide layer formed which protected direct asperityto-asperity contacts. Due to the formation of an oxide layer between counterfaces, lower $f$ is obtained [31]. Oxide layer breaks at higher load leading to severe abrasive or adhesive depending on the material combination, hardness, and composite surface roughness [31]. In past, the effect of normal load on $f$ has been discussed in detail [30,31]. In this section, wear mechanisms involved for obtaining higher friction at higher load and the evolution of topography parameters with sliding time for friction tests are discussed in detail. Figures 14(a)-14(c) represent SEM micrographs of AISI 304 steel, which are taken after 5 min of wear test. The EDS spectra for each micrographs are shown in Figs. 14(a)-14(c). The test conditions (normal load and speed) are also shown. The abrasive ploughing effect due to the presence of hard abrading particles on the counterface body can be clearly seen in Fig. 14(a). White region indicates the plastic deformation of asperities. Removal of AISI 304 material in form of plate like debris indicates the presence of delamination wear. As load increases from 20 to $40 \mathrm{~N}$, delamination wear and abrasion ploughing wear become predominant wear mechanisms, as shown in Figs. 14(b) and 14(c). An increase in surface damage due to higher three body abrasion and delamination wear results in higher friction coefficient at higher load. From EDS spectra in Figs. 14(d)-14(f), it can be seen that oxide
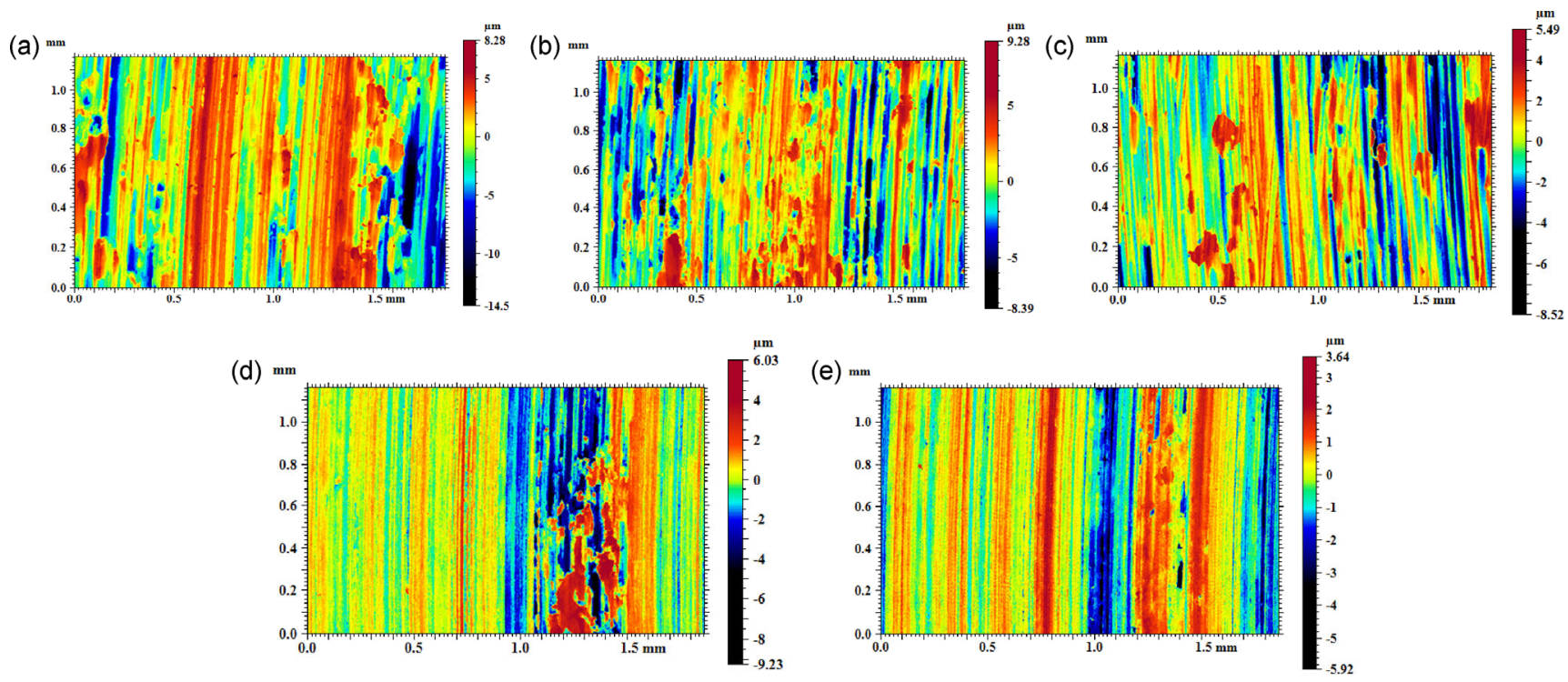

Fig. 13 Surface maps of flat pin (AISI 304) during friction tests after different sliding time: (a) $1 \mathrm{~min}$, (b) 2 min, (c) $3 \mathrm{~min}$, (d) 4 min, and (e) $5 \mathrm{~min}$. 
(a) $20 \mathrm{~N}, 200 \mathrm{rpm}$

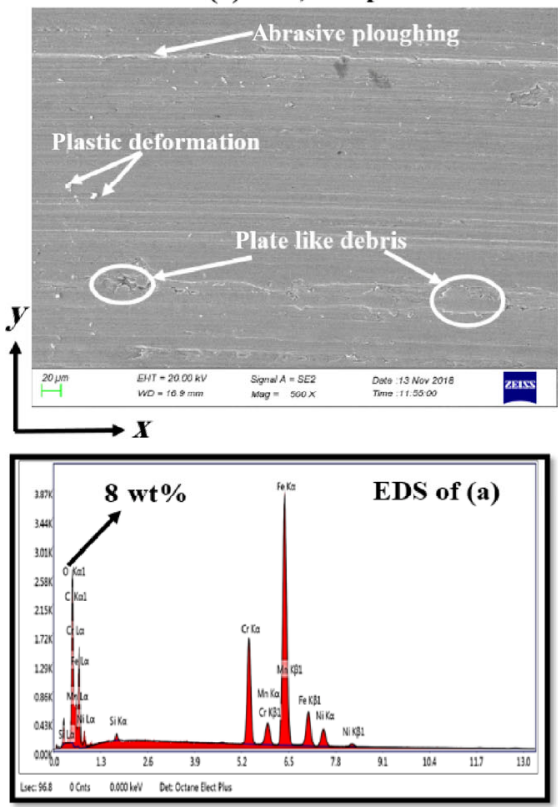

(b) $30 \mathrm{~N}, 200 \mathrm{rpm}$
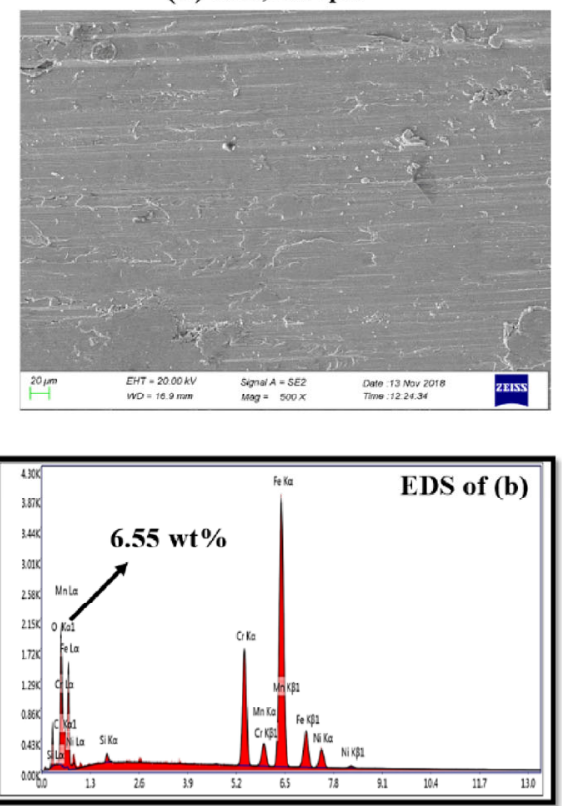

(c) $40 \mathrm{~N}, 200 \mathrm{rpm}$
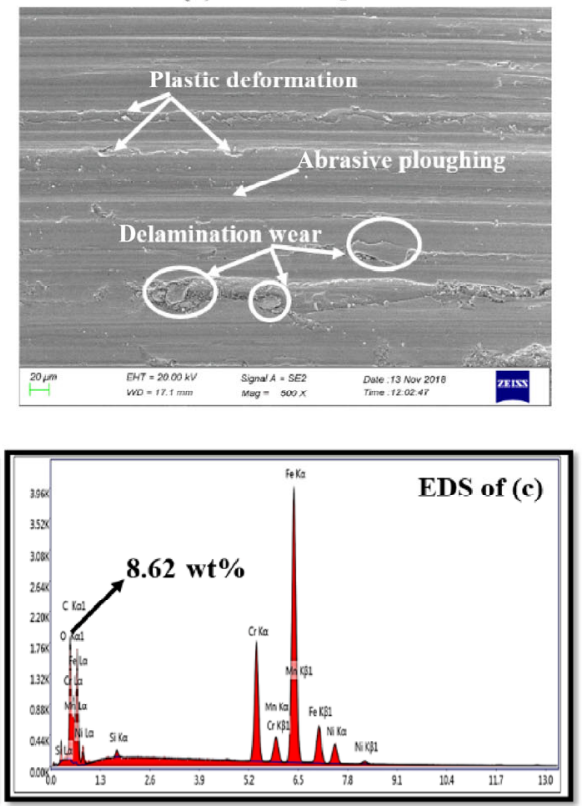

Fig. 14 SEM micrographs of AISI 304 steel pin under different normal loads at $N_{\text {rot }}=200$ rpm after 5 min wear test: (a) $F_{\mathrm{N}}=20 \mathrm{~N}$, (b) $F_{\mathrm{N}}=30 \mathrm{~N}$, and (c) $F_{\mathrm{N}}=40 \mathrm{~N}$ ( $x$ represents the sliding direction).

content (wt\%) decreases with an increase in load from 20 to $40 \mathrm{~N}$. Decrease in oxide contents clearly indicating the breaking of oxide layer at higher load.

Figure 15 shows the variation of $S_{q}$ with sliding time for different value of normal loads (20,30, and $40 \mathrm{~N}$ ). As illustrated in Fig. 15, $S_{q}$ roughness decreases with an increase in sliding time. For sliding time of $2 \mathrm{~min}$, the lowest value of $S_{q}$ is found for $40 \mathrm{~N}$ normal load. This may happen due to entrappement of asperities within the contact zone at lower load after $1 \mathrm{~min}$ of

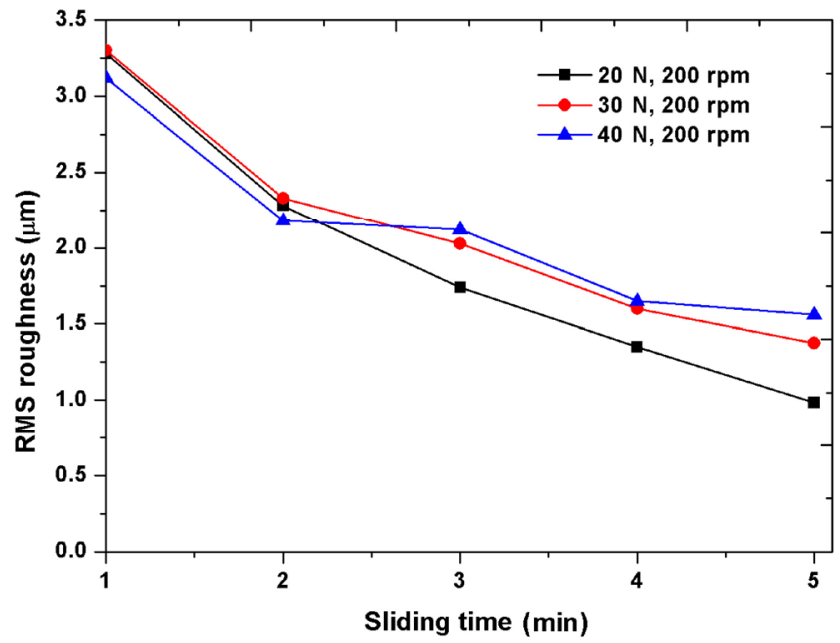

Fig. 15 Variation of $S_{q}$ with sliding time for the same speed and different loads. sliding time. An increase in load, increases the real contact area which diminishes the probability of entrappment of asperitis due to distribution of load in large contact area. After 2 min of sliding time, RMS roughness increases with an increase in normal load from 20 to $40 \mathrm{~N}$. Figure 16 represents the variation of RMS slope $\left(S_{d q}\right)$ with an increase in sliding time for different value of normal loads (20, 30, and $40 \mathrm{~N})$. It can be seen that the RMS slope decreases with an increase in sliding time. It can also be seen from Fig. 16 that $S_{d q}$

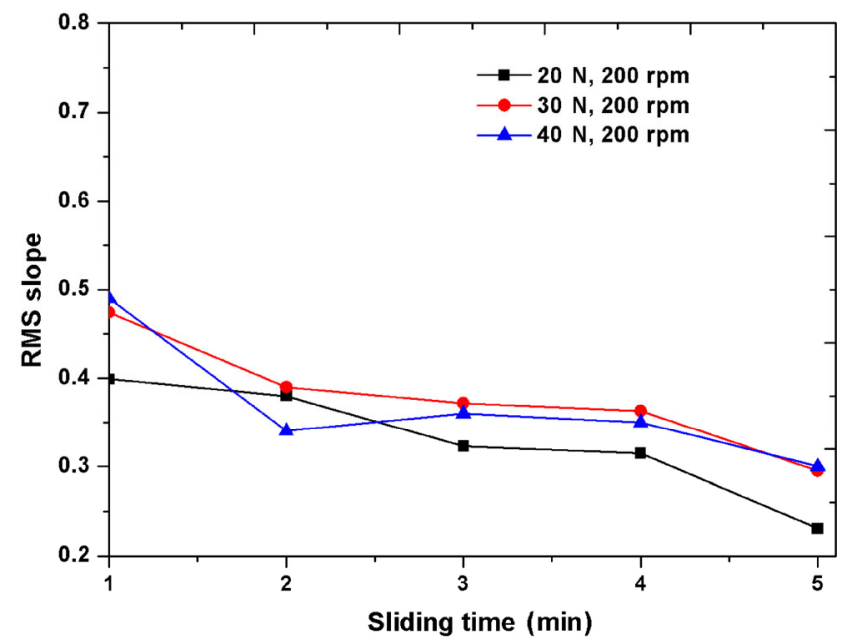

Fig. 16 Variation of $S_{d q}$ with sliding time for the same speed and different loads. 
reduces drasticaly for higher loads, whereas, for lower load fall gradually. Higher load causes initial severe plastic deformation and for lower load, both elastic and plastic deformation takes place resulting in gradual wear. As wear progresses, asperity removes from the pin surface (due to its lower hardness) which leads to decreases in roughness heights of the peaks. Due to asperity removal, surface becomes flattened resulting in decrease in RMS slope. Within the range of sliding time, at some time instant, a slight increase in value of RMS slope can be seen in Fig. 16 due to the occurrence of adhesive wear.

The variation of skewness $\left(S_{\text {sk }}\right)$ with an increase in sliding time can be seen from Fig. 17. Skewness decreases with an increase in sliding time and increases with an increase in normal load. Skewness represents the asymmetry in roughness heights with respect to the mean plane of the surface [25]. As wear progresses, $S_{\text {sk }}$ decreases due to the removal of asperity peaks. As asperity removes from the surface, the mean plane moves into the plane resulting in a more negative value of the skewness. It can be seen that for $40 \mathrm{~N}$ normal load, $S_{\text {sk }}$ steeply increases with 1 to $2 \mathrm{~min}$ of sliding time and then falls gradually for further an increase in sliding time. However, for low laods (20 and $30 \mathrm{~N}$ ), $S_{\text {sk }}$ first decreases very sharply within 1 to 2 min of sliding time and then increases between 2 to 3 min of sliding time and finally falls gradually for further an increase in sliding time from 3 to $5 \mathrm{~min}$. Since, high load causes steep change in asperity heights

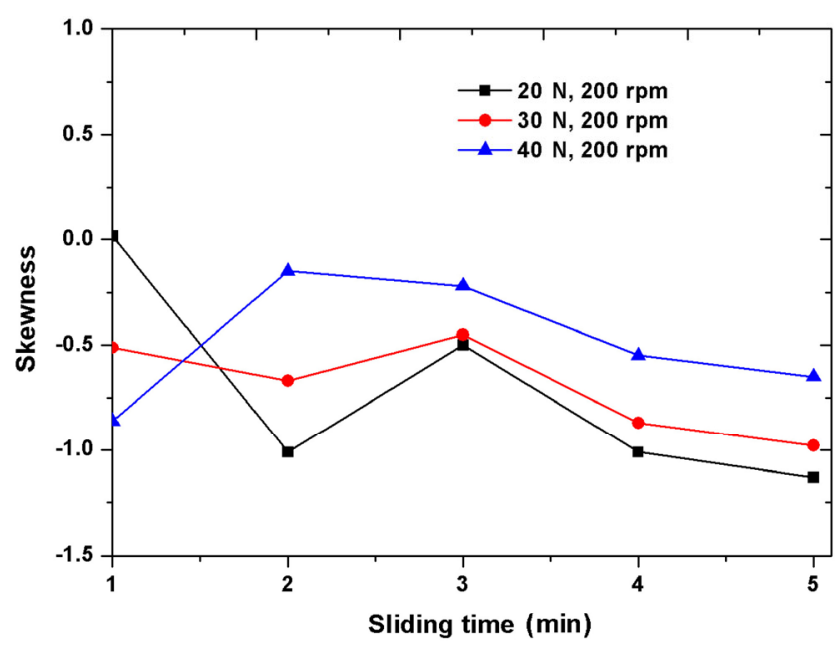

Fig. 17 Variation of $S_{\text {sk }}$ with sliding time for the same speed and different loads. resulting in gradual decrease in skewness value, however, low load, causes steep change in skewness initially followed by oscillatory changes (initially elastic then elastic-plastic, and finally plastic deformation). Another reason may be for this drastic change in skewness value is due to three-body abrasive wear. Because pin (AISI 304) has a lower hardness in comparison to counterface disc (AISI 52100) which minimize the possibility of sticking of counterface material on the pin surface. The variation of kurtosis $\left(S_{\mathrm{ku}}\right)$ with an increase in sliding time can be seen from Fig. 18. $S_{\mathrm{ku}}$ increases with an increase in sliding time. Within the range of sliding time, $S_{\mathrm{ku}}$ decreases with an increase in normal load from 20 to $40 \mathrm{~N}$. Kurtosis represents the 'peakedness' in roughness heights [25]. However, it can also be seen from Fig. 18 that kurtosis decreases for an increase in the sliding time from 4 to $5 \mathrm{~min}$.

Mean summit curvature $\left(\mathrm{S}_{\mathrm{sc}}\right)$ is an important parameter which is directly related to the flatness of the roughness peaks [32]. As mentioned in Section 3.2 that $R$ is inversely proportional to $S_{\text {sc. }}$. It is desirable in tribology to have a surface with high mean summit radius. A higher value of $R$ can minimize the possibility of plastic deformation of asperity during the first contact of rough surfaces [32,33]. Recently, Prajapati and Tiwari [22] showed from wear simulation that $R$ varies significantly during wear. Figure 19 shows the variation of $S_{\mathrm{sc}}$ with sliding time. In this work, $S_{\mathrm{sc}}$ is calculated according to the method described in Ref. [22]. $S_{\text {sc }}$ decreases with an increase in sliding time

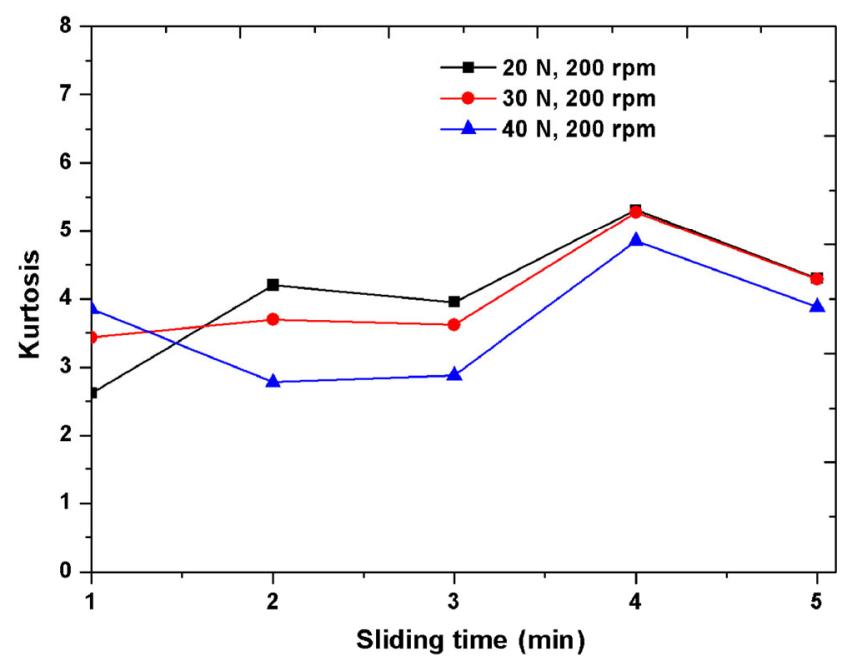

Fig. 18 Variation of $S_{\mathrm{ku}}$ with sliding time for the same speed and different loads. 


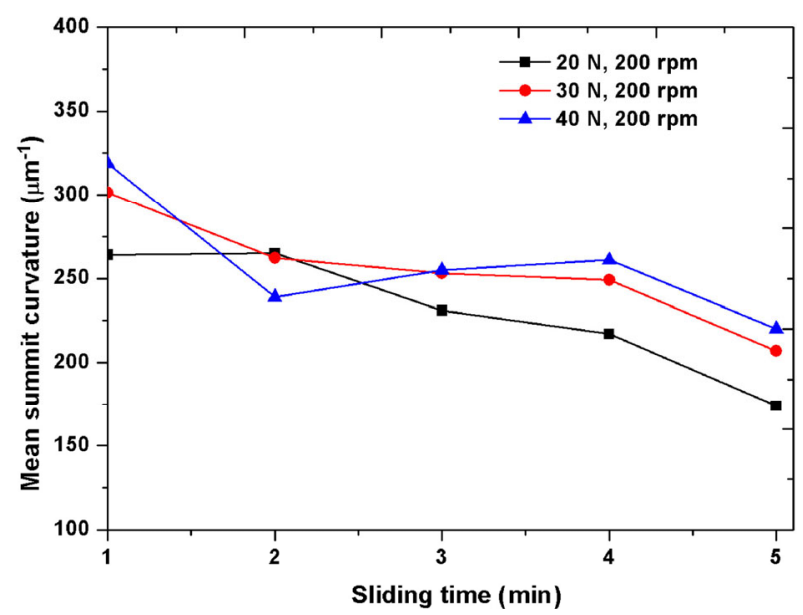

Fig. 19 Variation of $S_{\mathrm{sc}}$ with sliding time for the same speed and different loads.

and increases with an increase in normal load from 20 to $40 \mathrm{~N}$. For $40 \mathrm{~N}$ load, the value of $S_{\mathrm{sc}}$ at $2 \mathrm{~min}$ of sliding time is lower than the value of $S_{\mathrm{sc}}$ obtained at $20 \mathrm{~N}$. This may happen due to significant plastic deformation of the surface at higher load.

As mentioned in Sec. 3.2 that $S_{\text {al }}$ is used to get the spatial information of the rough surface. Any change in $S_{\text {al }}$ value leads to a change in topography parameters [34]. It has been shown in Ref. [35] that contact area, total normal load, and contact pressure significantly affect from autocorrelation length. Recently, it has been shown in Ref. [36] that $S_{a l}$ varies significantly during rolling contact fatigue. Figure 20 shows the variation of $S_{a l}$ with sliding time. The $S_{a l}$ decreases for some time and then increases with sliding time. This may happens due to entrappement of asperities

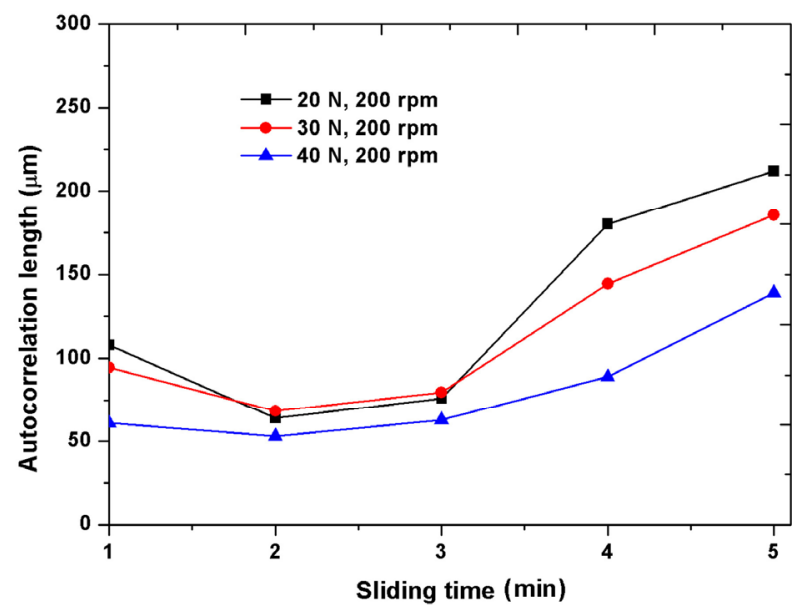

Fig. 20 Variation of $S_{\text {al }}$ with sliding time for the same speed and different loads. between 1 to 2 min of sliding time. When sliding time is further increased, entrapped asperities are flashed out from contact zone and due to simulatenously plastic deformation of asperties, there is less chance of entarppment of asperities. Due to which further decrease in autocorrelation length is not observed for every values of normal load $\left(F_{\mathrm{N}}=20-40 \mathrm{~N}\right)$. It can also be seen from Fig. 20 that within the range of sliding time, autocorrelation length decreases with an increase in normal load from 20 to $40 \mathrm{~N}$ which is due to more surface damage at higher loads.

\subsection{Correlation between friction coefficient and topography parameters}

This section shows the mutual effect of load and speed on friction and topography parameters. In the past, various studies have been reported on the use of factorial design to analyze the friction and wear coefficient for the various range of load and speed [37-40]. However, in those studies, the combined effect of load and speed on topography parameters which vary significantly during wear (as shown in Sections 3.2 and 3.3), were not reported. In this work, factorial design with custom response surface design (C-RSD) is used to demonstrate the effect of normal load and speed on friction coefficient and topography parameters. Two design parameters namely, normal load and velocity are used, and output such as friction coefficient and areal topography parameters are determined. A Minitab v.18.0 statistical software is used for the purpose of the analysis. For the two parameters (load and speed), nine experiments are generated. The parameters used in experiments and their associated levels are shown in Table 4. The experiment is repeated two times to ensure the trend on topography parameters for different value of load and speed, and the average value of topography parameters is reported. Experimental values obtained for friction coefficient and topography parameters are analyzed using analysis of variance (ANOVA). Empirical relationship for friction coefficient and topography parameters is obtained by fitting polynomial models. Second-order polynomial is used for relating the selected parameters with the response. Second-order polynomial equation is used to include the effect of curvature on response variables. The expression for 
Table 4 Factors and their associated levels.

\begin{tabular}{cccc}
\hline Factors & Level 1 & Level 2 & Level 3 \\
\hline Load $(L)$ & $20 \mathrm{~N}$ & $30 \mathrm{~N}$ & $40 \mathrm{~N}$ \\
Speed $(V)$ & $200 \mathrm{rpm}$ & $300 \mathrm{rpm}$ & $400 \mathrm{rpm}$ \\
\hline
\end{tabular}

second-order polynomial is given in Eq. (1):

$$
R_{\text {out }}=a+\sum a_{i} x_{i}+\sum a_{i i} x_{i}^{2}+\sum a_{i j} x_{i} x_{j}
$$

where $R_{\text {out }}$ is the response, and $a, a_{i}, a_{i i}$ and $a_{i j}$ are the coefficients which need to be determined from the regression analysis. The second term in Eq. (1) denotes the linear effect, the third term denotes the higherorder effect, and the fourth term denotes the interaction effect, respectively.

The regression equations in uncoded form for friction coefficient and areal topography parameters are shown in Appendix B. The parameters representing the goodness of fits such as $S$-value, $R$-sq, $R$-sq (adj.), and confidence interval $(\alpha)$ are also shown in each figure caption (Figs. 21-23). Parameters such as DF (degree of freedom), Adj SS (adjusted sum of square), Adj MS (adjusted mean square), F-value (F-stats), and $P$-value, obtained from ANOVA analysis are shown in Tables $5-10$. The total degrees of freedom ( $\mathrm{DF}=n-1$, where $n$ is number of observations) shows
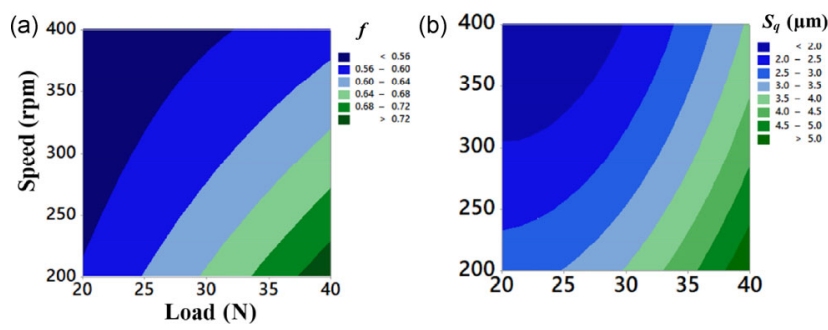

Fig. 21 Response surface plots of (a) friction coefficient (f), $S=$ $0.027, R$-sq $=93.81 \%, \alpha=0.05, R$-sq (adj.) $=83.49 \%$, (b) RMS roughness $\left(S_{q}\right), S=0.4, R$-sq $=96.17 \%, \alpha=0.05, R$-sq (adj.) $=$ $56.71 \%$.
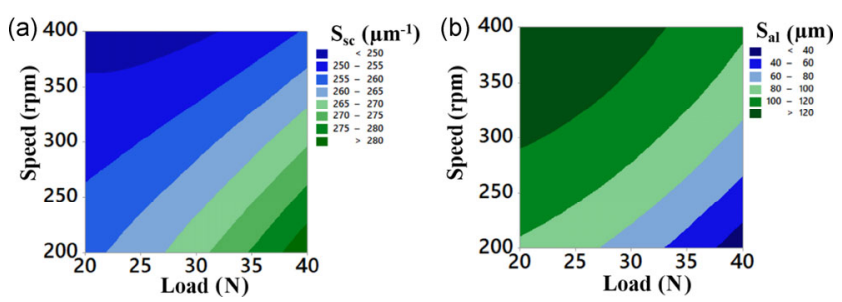

Fig. 22 Response surface plots of (a) mean summit curvature $\left(S_{\mathrm{sc}}\right), S=0.076, R$-sq $=92.31 \%, \alpha=0.05, R$-sq $(\operatorname{adj})=.83.49 \%$, (b) autocorrelation length $\left(S_{\mathrm{al}}\right), S=9.6, R$-sq $=96.86 \%, \alpha=0.05$, $R$-sq (adj.) $=91.63 \%$.
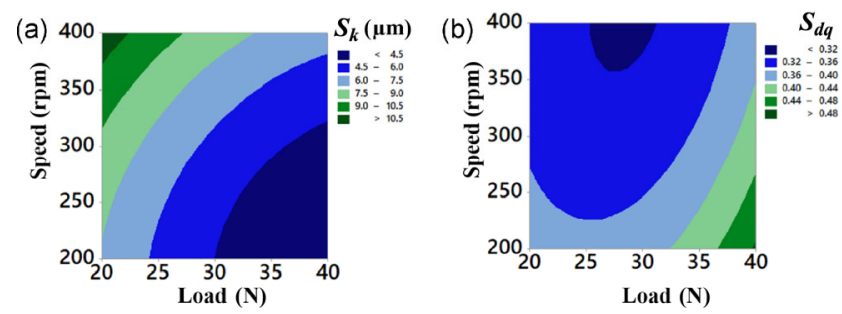

Fig. 23 Response surface plots of (a) core roughness depth $\left(S_{\mathrm{k}}\right)$, $S=0.64, R$-sq $=97.8 \%, \alpha=0.05, R$-sq (adj. $)=94.13 \%$; (b) RMS slope $\left(S_{\mathrm{dq}}\right), S=0.014, R$-sq $=98.43 \%, \alpha=0.05, R$-sq $(\operatorname{adj})=$. $86.69 \%$.

the amount of information in data. DF of a factor $(p-1$, where $p$ is the number of inoput variables) represents how much information is used by a factor [40]. Adj SS measures the variation of a term, given all other terms in the model [40]. Adj MS is obtained by dividing the Adj SS to DF of factor [40]. F-value is calculated by dividing the Adj MS to mean square error (MSE) [40]. $P$-value is calculated from $F$-value and used to determine whether a factor is statistically significant or not [40]. It has been mentioned in Refs. [38-40] that for a factor to be effective, the $P$ value should be less than 0.05 (for significance level, $\alpha=5 \%$ ).

\subsubsection{Effect of load and speed on $f$ and $S_{q}$}

The relationship between the $f$ and two independent variables (load and speed) is shown in Fig. 21(a). The response surface can be represented either in threedimensional space or as a contour plot, which helps to analyze the trend of response. Figure 21(a) shows the contour plot of the friction coefficient as a function of load and speed. Within the range of load and speed, the lowest $f$ is obtained for low load $(20 \mathrm{~N})$ and high speed (400 rpm) conditions. It can be seen from Fig. 21(a) that for a particular value of speed, the friction coefficient increases with an increase in load from 20 to $40 \mathrm{~N}$. This happens due to an increase in surface damage (surface roughness increases with increase in load) at higher load. The real contact area increases with an increase in normal load resulting in more asperity-to-asperity contacts ultimately more surface damage. It can also be seen that for a particular value of normal load, the friction coefficient decreases with an increase in rotational speed. The reason for getting lower $f$ is quick removal of contacting asperities at higher speed. The $S_{q}$ variation with normal load and speed is shown in Fig. 21(b). 
The region of the lowest $S_{q}$ lies in the range of 350$400 \mathrm{rpm}$. As rotational speed increase, asperities remove quickly from the contacting surface resulting in reduction in roughness heights. Due to the decrease in roughness heights, RMS roughness decreases at higher speed. Later on, it will be shown in Section 3.5 that high rotational speed results in lower adhesive and abrasive wear. As illustrated in Fig. 21(b) that $S_{q}$ increases with an increase in load from 20 to $40 \mathrm{~N}$. The reason for increasing the RMS roughness with an increase in load is previously explained in Section 3.3. It can be inferred from Figs. 21(a) and 21(b) that $S_{q}$ is positively correlated with $f$. The ANOVA for the $f$ is presented in Table 5. It can be inferred from Table 5 that load $(L)$ and speed $(V)$ significantly affect $(P$-value $<0.05)$ the $f$ which can also be seen from Fig. 21(a). However, interaction $(L \times V)$ and quadratic $\left(V^{2}, L^{2}\right)$ terms or variables are not adequate $(P$-value $>0.05)$. This is the reason for getting a linear contour map of friction coefficient (Fig. 21(a)). The result of ANOVA analysis for $S_{q}$ is shown in Table 6. It can be seen that $P$-value for factors $L$ and $V$ are 0.017 and 0.029 , respectively, indicating significant effect of

Table 5 Analysis of variance for $f$.

\begin{tabular}{cccccc}
\hline Source & DF & Adj SS & Adj MS & $F$-value & $P$-value \\
\hline$L$ & 1 & 0.018150 & 0.018150 & 23.14 & 0.017 \\
$V$ & 1 & 0.012150 & 0.012150 & 15.49 & 0.029 \\
$L \times L$ & 1 & 0.000272 & 0.000272 & 0.35 & 0.597 \\
$V \times V$ & 1 & 0.000272 & 0.000272 & 0.35 & 0.597 \\
$L \times V$ & 1 & 0.005625 & 0.005625 & 7.17 & 0.075 \\
Error & 3 & 0.002353 & 0.000784 & - & - \\
Total & 8 & 0.038822 & - & - & - \\
\hline
\end{tabular}

Table 6 Analysis of variance for RMS roughness $\left(S_{q}\right)$

\begin{tabular}{cccccc}
\hline Source & DF & Adj SS & Adj MS & $F$-value & $P$-value \\
\hline$L$ & 1 & 8.0968 & 8.09682 & 49.01 & 0.006 \\
$V$ & 1 & 3.4808 & 3.48082 & 21.07 & 0.019 \\
$L \times L$ & 1 & 0.6844 & 0.68445 & 4.14 & 0.135 \\
$V \times V$ & 1 & 0.0612 & 0.06125 & 0.37 & 0.586 \\
$L \times V$ & 1 & 0.1190 & 0.11902 & 0.72 & 0.458 \\
Error & 3 & 0.4956 & 0.16521 & - & - \\
Total & 8 & 12.9380 & - & - & - \\
\hline
\end{tabular}

load and speed on $S_{q} . P$-value for iteraction $(L \times V)$ and quadratic $\left(L^{2}, V^{2}\right)$ terms are $0.458,0.135$, and 0.586 , respectively, indicating the trivial effect on $S_{q}$. It can also be seen from Table 6 that $P$-value of quadratic terms for RMS roughness is higher than those obtained for friction coefficient. Due to significant effect of quadratic terms, $S_{q}$ varies non-lineraly with load and speed.

\subsubsection{Effect of load and speed on $S_{\mathrm{sc}}$ and $S_{\mathrm{al}}$}

The combined effect of load and speed on $S_{\mathrm{sc}}$ is shown in Fig. 22(a). It can be seen that the lowest region of $S_{\text {sc }}$ occurred for the speed between 350 and $400 \mathrm{rpm}$. Whereas, the highest $S_{\mathrm{sc}}$ is found for low load $20 \mathrm{~N}$ and low speed $200 \mathrm{rpm}$ conditions. It can also be seen from Fig. 22(a) that $S_{\mathrm{sc}}$ increases with an increase in the normal load. It can be inferred that to get less friction and wear the component should be run at the low load and high-speed condition. However, very high speed may result in high adhesion due to very large frictional heat (the situation at which contact temperature become higher than the melting point of the material). Figure 22(b) represents the contour plot of $S_{\text {al }}$ for different values of load and speed condition. As illustrated in Fig. 22(b), $S_{\text {al }}$ is the highest towards high speed and low load region. Within the range of speed (200 to $400 \mathrm{rpm}$ ), the lowest autocorrelation length is found for the high normal load $(40 \mathrm{~N})$. It can also be seen the $S_{\text {al }}$ decreases with an increase in load. It is shown in Section 3.2 that $S_{\text {al }}$ increases with an increase in sliding time due to an increase in the flatness of the roughness peaks. From contour plot (Fig. 22(b)) of $S_{\text {al, }}$ it is clear that the component running at low load and high-speed condition exhibits very high correlation length. It can be inferred that rough surfaces with higher correlation length may exhibit significant improvement under mixed-lubrication regime. The ANOVA result for mean summit curvature is presented in Table 7. It can be seen that $S_{\text {sc }}$ significantly depends on load and speed. Iteraction $(L \times V)$ of speed and load shows little effect on mean summit curvature. However, qudratic $\left(L^{2}, V^{2}\right)$ terms do not show any significant effect on mean summit curvature. It can be seen from Table 8 that $L$ and $V$ significantly affect the $S_{\text {al }}$. It can also be seen from Table 8 that $P$-value of quadratic $\left(L^{2}, V^{2}\right)$ and interaction 
Table 7 Analysis of variance for $S_{\mathrm{sc}}$.

\begin{tabular}{cccccc}
\hline Source & DF & Adj SS & Adj MS & $F$-value & $P$-value \\
\hline$L$ & 1 & 400.17 & 400.167 & 13.03 & 0.036 \\
$V$ & 1 & 560.67 & 560.667 & 18.26 & 0.024 \\
$L \times L$ & 1 & 16.06 & 16.056 & 0.52 & 0.522 \\
$V \times V$ & 1 & 0.22 & 0.222 & 0.01 & 0.938 \\
$L \times V$ & 1 & 81.00 & 81.000 & 2.64 & 0.203 \\
Error & 3 & 92.11 & 30.704 & - & - \\
Total & 8 & 1150.22 & - & - & - \\
\hline
\end{tabular}

Table 8 Analysis of variance for $S_{\mathrm{al}}$.

\begin{tabular}{cccccc}
\hline Source & DF & Adj SS & Adj MS & $F$-value & $P$-value \\
\hline$L$ & 1 & 3408.2 & 3408.17 & 36.82 & 0.009 \\
$V$ & 1 & 4428.2 & 4428.17 & 47.84 & 0.006 \\
$L \times L$ & 1 & 144.5 & 144.50 & 1.56 & 0.300 \\
$V \times V$ & 1 & 144.5 & 144.50 & 1.56 & 0.300 \\
$L \times V$ & 1 & 441.0 & 441.00 & 4.76 & 0.117 \\
Error & 3 & 277.7 & 92.56 & - & - \\
Total & 8 & 8844.0 & - & - & - \\
\hline
\end{tabular}

$(L \times V)$ terms for the autocorrelation length is more than the mean summit curvature. As a result, nonlinearity in contour plot of autocorrelation length is more than contour plot of mean summit curvature (Figs. 22(a) and 22(b)).

\subsubsection{Effect of load and speed on $S_{k}$ and $S_{d q}$}

The core roughness depth $\left(S_{k}\right)$ is a hybrid parameter calculated from the areal bearing ratio curve [41]. $S_{k}$ is calculated as the difference of roughness heights at the areal material ratio values between $0 \%$ and $100 \%$ on the equivalent line. The parameter $S_{k}$ measures the core of the surface with predominant peaks and valleys removed. It is a core part of the surface over which applied normal load is distributed on the surface. In tribology, a higher value of $S_{k}$ represents the higher bearing load capacity of the surface [29]. Figure 23(a) represents the contour plot of core roughness depth. It can be seen that within range of the normal load, $S_{k}$ value increases with an increase in speed. It can also be seen that $S_{k}$ value decreases with an increase in normal load. As load increases from 20 to $40 \mathrm{~N}$, the contact area increases, resulting in an increase in the number of contacting asperity.
An increase in the number of contacting asperity increases the peak height above the core roughness and correspondingly core roughness depth decreases. Whereas, at high speed, roughness peaks above the core are worn out resulting in an increase in core roughness depth. The variation of the $S_{d q}$ for the range of load and speed is presented in Fig. 23(b). It can be seen that RMS slope decreases with an increase in speed. The region of the lowest RMS slope can be seen between 350 and $400 \mathrm{rpm}$. It is known that the RMS slope of the surface will be high if the roughness peaks are sharp and vice versa [42]. At low-speed, welded junction is formed due to high shear stresses between contacting asperities which required high force to break these junctions during sliding. As a result, very small material is removed from contacting bodies and sharpness of roughness peaks persist resulting in high RMS slope. However, at high-speed, roughness peaks are worn out very quickly resulting in a decrease in RMS slope of the surface. From Tables 9 and 10, it can be seen that $S_{k}$ and $S_{d q}$ are significantly affected by load and speed. However, interaction $(L \times V)$ and qudratic $\left(L^{2}, V^{2}\right)$ terms are not much significant for both $S_{k}$ and $S_{d q}$.

Table 9 Analysis of variance for $S_{k}$.

\begin{tabular}{cccccc}
\hline Source & DF & Adj SS & Adj MS & $F$-value & $P$-value \\
\hline$L$ & 1 & 31.4188 & 31.4188 & 80.36 & 0.003 \\
$V$ & 1 & 21.3193 & 21.3193 & 54.53 & 0.005 \\
$L \times L$ & 1 & 1.0035 & 1.0035 & 2.57 & 0.207 \\
$V \times V$ & 1 & 1.0609 & 1.0609 & 2.71 & 0.198 \\
$L \times V$ & 1 & 0.0529 & 0.0529 & 0.14 & 0.737 \\
Error & 3 & 1.1729 & 0.3910 & - & - \\
Total & 8 & 56.0284 & - & - & - \\
\hline
\end{tabular}

Table 10 Analysis of variance for $S_{d q}$.

\begin{tabular}{cccccc}
\hline Source & DF & Adj SS & Adj MS & $F$-value & $P$-value \\
\hline$L$ & 1 & 400.17 & 400.167 & 13.03 & 0.036 \\
$V$ & 1 & 560.67 & 560.667 & 18.26 & 0.024 \\
$L \times L$ & 1 & 16.06 & 16.056 & 0.52 & 0.522 \\
$V \times V$ & 1 & 0.22 & 0.222 & 0.01 & 0.938 \\
$L \times V$ & 1 & 81.00 & 81.000 & 2.64 & 0.203 \\
Error & 3 & 92.11 & 30.704 & - & - \\
Total & 8 & 1150.22 & - & - & - \\
\hline
\end{tabular}


From the Sections 3.4.1 to 3.4.3, it can be inferred that $f$ is positively correlated with $S_{q}, S_{d q}$, and $S_{\mathrm{sc}}$. Whereas, $S_{k}$ and $S_{\text {al }}$ are negatively correlated with $f$. Previously, optical microscope and SEM have been used as basis for analyzing the wear mechanisms and by analyzing those micrographs. The reason for obtaining variation in the friction coefficient under different conditions has been reported [5-11, 14, 19, 30, 31, 37]. In this work, change in the $f$ is explained on the basis of the evolution of areal topography parameters. However, surface morphology is also presented in Section 3.5 to confirm the hypothesis made to explain the variation in topography parameters under different load and speed conditions.

\subsection{Surface morphology}

After performing friction tests for different operating conditions. The pin samples are cleaned using ultrasonic cleaner for $15 \mathrm{~min}$ and dried by hot air. SEM is used for morphological analysis of worn surfaces. The worn surfaces are measured in secondary electron emission mode and $20 \mu \mathrm{m}$ scale which provides the magnification of 500×. Figures 24(a)-24(i) represent micrographs of AISI 304 steel after friction tests at different load and speed conditions. The load and speed values are shown at the top of each figure. It can be seen from Figs. 24(a)-24(c) that the flatness of surface increases as speeds increase from 200 to $400 \mathrm{rpm}$. The abrasive ploughing marks can be clearly seen indicating the occurrence of abrasive wear. However, surface damage due to abrasive ploughing decreases with an increase in speed. The effect of load on AISI 304 surface can also be seen from Figs. 24(a), 24(d), and $24(\mathrm{~g})$. For a constant speed (200 rpm), formation of the plate-like debris increases with an increase in load from 20 to $40 \mathrm{~N}$ indicating an increase in (a) $20 \mathrm{~N}, 200 \mathrm{rpm}$

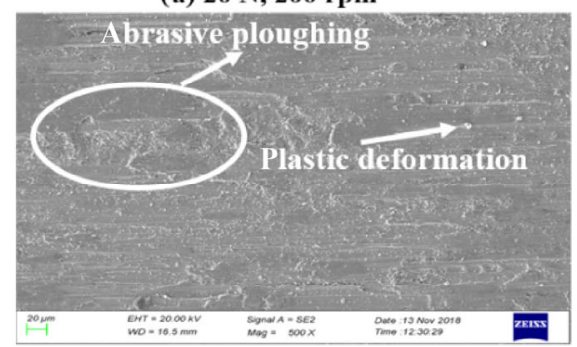

(d) $30 \mathrm{~N}, 200 \mathrm{rpm}$

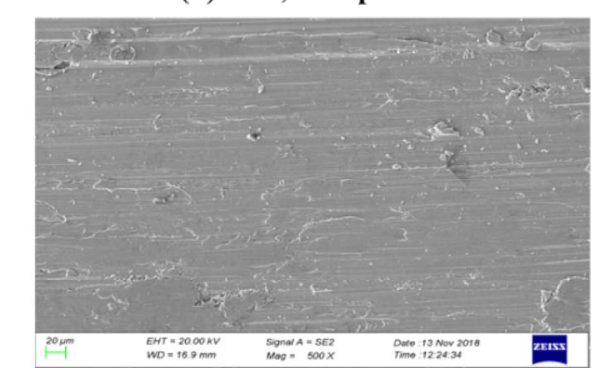

(g) 40 N, 200 rpm

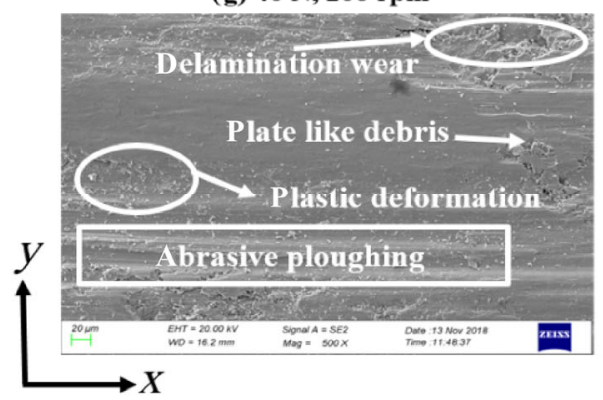

(b) $20 \mathrm{~N}, 300 \mathrm{rpm}$

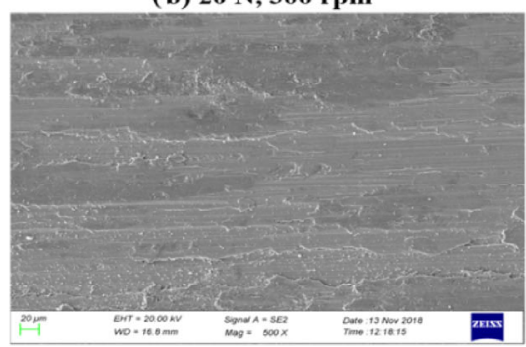

(e) $30 \mathrm{~N}, 300 \mathrm{rpm}$

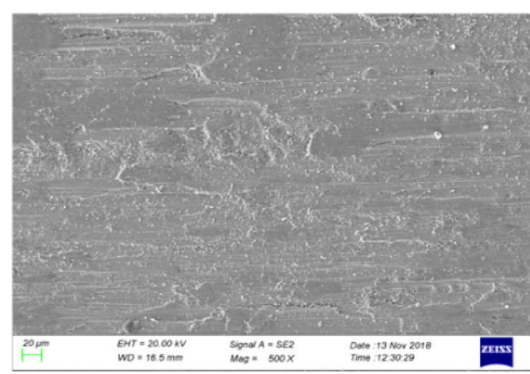

(h) $40 \mathrm{~N}, 300 \mathrm{rpm}$

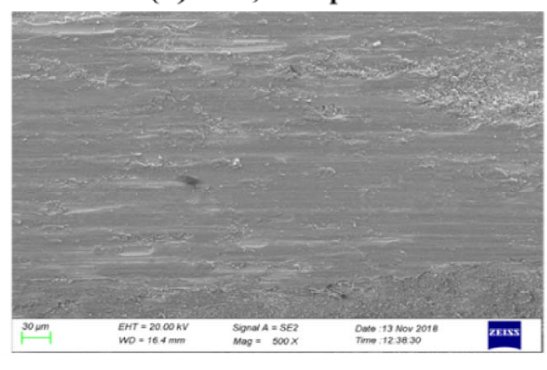

(c) $20 \mathrm{~N}, 400 \mathrm{rpm}$

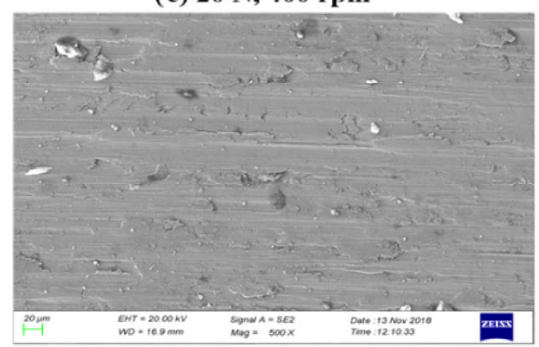

(f) $30 \mathrm{~N}, 400 \mathrm{rpm}$

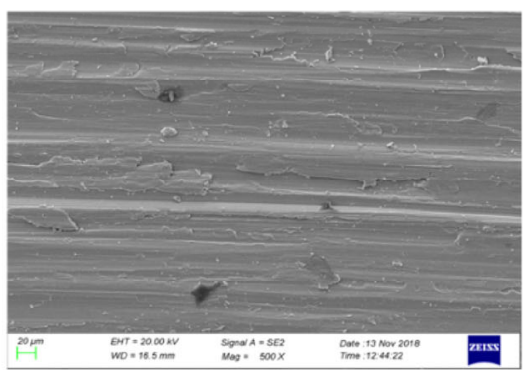

(i) $40 \mathrm{~N}, 400 \mathrm{rpm}$

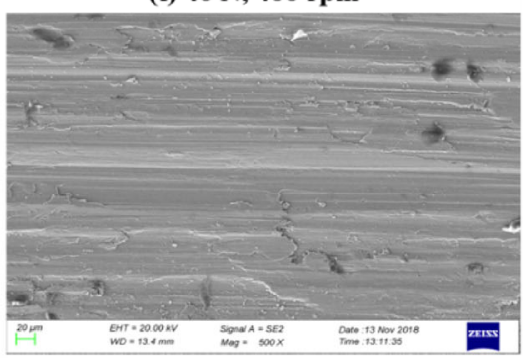

Fig. 24 SEM micrographs of AISI 304 steel for different normal loads under the speed = 200, 300, and $400 \mathrm{rpm}$. (a-c) $20 \mathrm{~N}$, (d-f) $30 \mathrm{~N}$, and $(\mathrm{g}-\mathrm{i}) 40 \mathrm{~N}$ ( $x$ represents the sliding direction). 
delamination wear. At higher load, plastic deformation of asperities can also be seen from Fig. 24(g). The delamination wear and plastic deformation of asperities decreases with an increase in speed from 200 to $400 \mathrm{rpm}$ (Figs. 24(g)-24(i)). It can also be seen from Fig. 24(a) that abrasive marks is minimal on AISI 304 steel surface at $20 \mathrm{~N}$ load and $200 \mathrm{rpm}$ speed due to adhesive wear. Whereas, at very high load and high-speed condition (40 N and $400 \mathrm{rpm}$ ), only abrasive marks are visible due to abrasive ploughing wear (see Fig. 24(i)). It can also be seen that resulting surface after wear test become flattened due to heavy plastic deformation of asperities. Figures 25(a)-25(c) represent SEM micrographs of the AISI 304 pin surface after wear test at the same speed (200 rpm) and different load $(20,30$, and $40 \mathrm{~N})$ conditions. The schematic of SEM inspected area is also shown in Fig. 25. The red circle shows the wedged material flowed outside from the contact zone. The dotted line indicates the boundary of the contact zone. It can be seen that abrasive ploughing mechanism and delamination wear are dominant wear mechanisms as normal load increases from 20 to $40 \mathrm{~N}$. At higher load, plastic deformation of asperity can be also observed from Figs. 25(b) and 25(c). Increasing surface damage (due to an increase in plastic deformation, abrasive ploughing, and delamination wear) with an increase in normal load is responsible for getting higher friction coefficient.

\section{Conclusions}

In this work, variation of areal topography parameters for AISI 304 steel during wear process is studied. Short duration tests of 2 min sliding time are performed in this work to make the pin surface flat. It is shown that short duration tests can be considered as initial running-in of pin surfaces. For different load and speed conditions, friction tests are performed on flat pin surfaces obtained from short duration tests. The variation of areal topography parameters with sliding time for different normal load is discussed in detail. It is found that RMS roughness, skewness, and mean summit curvature decrease with an increase in sliding time. Whereas, autocorrelation length and kurtosis increase with an increase in sliding time. Factorial design with C-RSD is used in this work to determine the combined effect of load and speed on friction coefficient and topography parameters. It is concluded that $S_{q}, S_{\mathrm{sc}}$, and root mean square slope $\left(S_{q}\right)$ are positively correlated with $f$. Whereas, negative correlation is found between $f$ and $S_{\text {al, }}$ and $S_{k}$. From (a) $20 \mathrm{~N}, 200 \mathrm{rpm}$

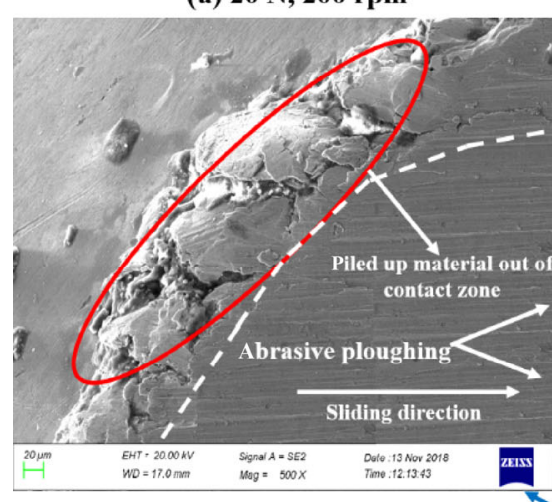

(b) $30 \mathrm{~N}, 200 \mathrm{rpm}$

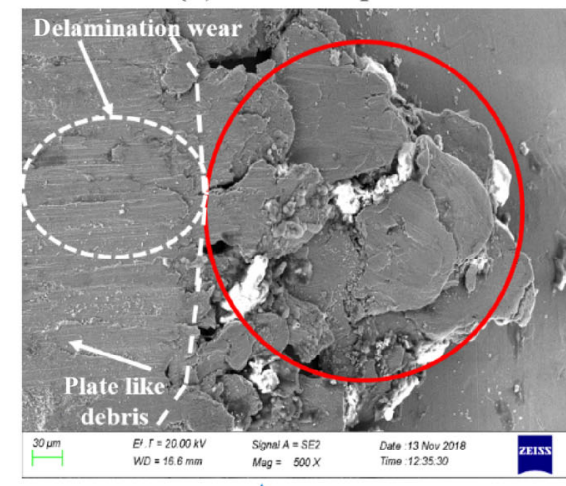

(c) $40 \mathrm{~N}, 200 \mathrm{rpm}$

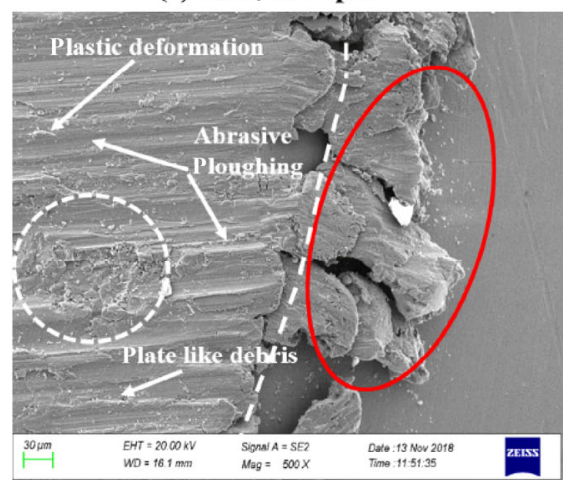

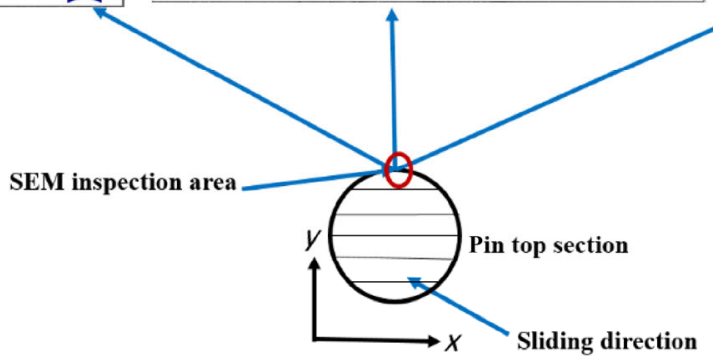

Fig. 25 SEM micrographs of AISI 304 steel for different normal loads under the speed of $200 \mathrm{rpm}$ : (a) $20 \mathrm{~N}$, (b) $30 \mathrm{~N}$, and (c) $40 \mathrm{~N}$. 
SEM analysis, it is found that abrasive ploughing and delamination wear are the dominant wear mechanisms in AISI 304 steel. At high normal load and low speed, abrasive ploughing and plastic deformation become significant. Whereas, delamination wear and plastic deformation are not much significant at low load and high-speed conditions. It is realized that interrupted type tests limit the optimum prediction of topography parameters. Other techniques such as replication using polymer compound are further required for topography measurement without interrupting the test specimens. This aspect will be discussed in ongoing research.

\section{Appendix}

\section{A Brief description of areal (3D) topography parameters}

The measured surface from optical profiler is denoted by $z(x, y)$. The surface after defining the mean plane is denoted by $\eta(x, y)$. The relation between residual surface and measured surface is given in Eq. (A1).

$$
\eta(x, y)=z(x, y)-f(x, y)
$$

In this work, residual surface, $\eta(x, y)$ is used to calculate the roughness parameters. The roughness parameters used in this study are briefly described below.

\section{Root mean square (RMS) roughness $\left(S_{q}\right)$}

RMS roughness measures the standard deviation of roughness heights. It is important to describe the surface roughness by statistical methods. For a discrete residual surface, $\eta\left(x_{i}, y_{i}\right)$, the statistical expression for determining RMS roughness is given in Eq. (A2) [15].

$$
S_{q}=\sqrt{\frac{1}{M N} \sum_{i=1}^{M} \sum_{j=1}^{N} z^{2}\left(x_{i}, y_{i}\right)}
$$

\section{Skewness $\left(S_{\text {sk }}\right)$}

Skewness measures the asymmetry of surface deviation from the mean plane [39]. For a discrete residual surface, $\eta\left(x_{i}, y_{i}\right)$, the statistical expression for determining $S_{\text {sk }}$ is given in Eq. (A3) [15].

$$
S_{\mathrm{sk}}=\frac{1}{M N S_{q}^{3}} \sum_{i=1}^{M} \sum_{j=1}^{N} z^{3}\left(x_{i}, y_{i}\right)
$$

\section{Kurtosis $\left(S_{\text {ku }}\right)$}

Kurtosis measures the 'peakedness' or 'sharpness' of the roughness heights distribution. For a discrete residual surface, $\eta\left(x_{i}, y_{i}\right)$, the statistical expression for determining kurtosis is given in Eq. (A4) [15].

$$
S_{\mathrm{ku}}=\frac{1}{M N S_{q}^{4}} \sum_{i=1}^{M} \sum_{\mathrm{j}=1}^{N} z^{4}\left(x_{i}, y_{i}\right)
$$

\section{Shortest autocorrelation length $\left(S_{\mathrm{al}}\right)$}

It is defined as the shortest $S_{\text {al }}$ during which areal autocorrelation length (AACF) decay to 0.2 in any possible direction. The expression for determining $S_{\text {al }}$ is given in Eq. (A5) [15].

$$
S_{\mathrm{al}}=\min \left(\sqrt{\tau_{x}^{2}+\tau_{y}^{2}}\right), \operatorname{AACF}\left(\tau_{x}, \tau_{y}\right) \leq 0.2
$$

\section{RMS slope $\left(S_{d q}\right)$}

It is the RMS slope of the surface within sample area. For a discrete residual surface, $\eta\left(x_{i}, y_{i}\right)$, the statistical expression for determining $S_{d q}$ is given in Eq. (A6) [15].

$$
\begin{aligned}
S_{d q}= & \sqrt{\frac{1}{(M-1)(N-1)}} \\
& \times \sqrt{\sum_{i=1}^{M} \sum_{j=1}^{N}\left[\left(\frac{z\left(x_{i}, y_{i}\right)-z\left(x_{\mathrm{i}-1}, y_{i}\right)}{\Delta x}\right)^{2}+\left(\frac{z\left(x_{i}, y_{i}\right)-z\left(x_{i}, y_{i-1}\right)}{\Delta y}\right)^{2}\right]}
\end{aligned}
$$

\section{Mean summit radius $(R)$}

It is defined as average of principle curvature of summits within sample area. For a discrete residual surface, $\eta\left(x_{i}, y_{i}\right)$, the statistical expression for determining $R$ is given in Eq. (A7) [15].

$$
\begin{aligned}
S_{\mathrm{sc}}= & -\frac{1}{2 n} \sum_{k=1}^{n}\left(\frac{\left.z\left(x_{p+1}, y_{q}\right)+z\left(x_{p-1}, y_{p}\right)-2 z\left(x_{p}, y_{q}\right)\right)}{\Delta x^{2}}+\right. \\
& \left.\frac{z\left(x_{p}, y_{q+1}\right)+z\left(x_{p}, y_{q-1}\right)-2 z\left(x_{p}, y_{q}\right)}{\Delta y^{2}}\right)
\end{aligned}
$$

For any summit located at $x_{p}$ and $y_{q}$, the mean summit radius can be obtained by taking inverse of mean summit curvature $\left(R=1 / S_{\text {sc }}\right)$. 


\section{B Regression equations for friction coefficient $(f)$ and topography parameters}

$$
\begin{aligned}
f= & 0.48-0.0022 L+0.00103 V+0.00015 L^{2}+ \\
& 0.000001 V^{2}-0.00004 L V
\end{aligned}
$$

$S_{\mathrm{al}}=-294.2-10.63 \mathrm{~L}+1.097 \mathrm{~V}+0.085 \mathrm{~L}^{2}+0.00085 \mathrm{~V}^{2}-$ $0.01054 L V$

$S_{q}=9.09-0.415 L+0.0023 V+0.00585 L^{2}+0.000018 V^{2}-$ $0.000172 L V$

$S_{k}=16.36-0.170 L+0.0586 V+0.00722 L^{2}+$ $0.000072 V^{2}-0.000115 L V$

$S_{d q}=0.831-0.0313 L-0.000083 V+0.000525 L^{2}+$

$$
0.000001 V^{2}-0.000013 L V
$$

$S_{\mathrm{sc}}=4.051+0.0193 L-0.00298 \mathrm{~V}-0.000371 L^{2}+$

$$
0.0000 V^{2}+0.00005 L V
$$

Open Access This article is licensed under a Creative Commons Attribution 4.0 International Li-cense, which permits use, sharing, adaptation, distribution and reproduction in any medium or for-mat, as long as you give appropriate credit to the original author(s) and the source, provide a link to the Creative Commons licence, and indicate if changes were made.

The images or other third party material in this article are included in the article's Creative Commons licence, unless indicated otherwise in a credit line to the material. If material is not in-cluded in the article's Creative Commons licence and your intended use is not permitted by statutory regulation or exceeds the permitted use, you will need to obtain permission directly from the copyright holder.

To view a copy of this licence, visit http://creativecommons.org/licenses/by/4.0/.

\section{References}

[1] Holmberg K, Erdemir A. Influence of tribology on global energy consumption, costs and emissions. Friction 5(3): 263-284 (2017)
[2] Holmberg K, Kivikytö-Reponen P, Härkisaari P, Valtonen $\mathrm{K}$, Erdemir A. Global energy consumption due to friction and wear in the mining industry. Tribol Int 115: 116-139 (2017)

[3] Holmberg K, Andersson P, Nylund N O, Mäkelä K, Erdemir A. Global energy consumption due to friction in trucks and buses. Tribol Int 78: 94-114 (2014)

[4] Dzierwa A, Pawlus P, Zelasko W. Comparison of tribological behaviors of one-process and two-process steel surfaces in ball-on-disc tests. Proc Inst Mech Eng Part J J Eng Tribol 228(10): 1195-1210 (2014)

[5] Velicu R, Bobancu S, Popa S. Geometry and kinematics of the plate on disk contact type influencing friction measurements on UMT tribometer. IOP Conf Ser Mater Sci Eng 147(1): 012042 (2016)

[6] Windarta. Application pin-on-disc method for wear rate prediction on interaction between rail and wheel. IOP Conf Ser Mater Sci Eng 403(1): 012099 (2018)

[7] Garcia-Prieto I, Faulkner M D, Alcock J R. The influence of specimen misalignment on wear in conforming pin on disk tests. Wear 257(1-2): 157-166 (2004)

[8] Alias S K, Ahmad S, Abdullah B, Pahroraji H F, Hamami G. Effect of temperature variation on wear behaviour of austenitic stainless steel. IOP Conf Ser Mater Sci Eng 160(1): 012026 (2016)

[9] Bregliozzi G, Ahmed S I U, Di Schino A, Kenny J M, Haefke H. Friction and wear behavior of austenitic stainless steel: Influence of atmospheric humidity, load range, and grain size. Tribol Lett 17(4): 697-704 (2004)

[10] Kumar S, Mukhopadhyay A. Effect of microstructure on the wear behavior of heat treated ss-304 stainless steel. Tribol Ind 38(4): 445-453 (2016)

[11] Nafar Dehsorkhi R, Sabooni S, Karimzadeh F, Rezaeian A, Enayati $\mathrm{M} \mathrm{H}$. The effect of grain size and martensitic transformation on the wear behavior of AISI 304L stainless steel. Mater Des 64: 56-62 (2014)

[12] Sun Y. Sliding wear behaviour of surface mechanical attrition treated AISI 304 stainless steel. Tribol Int 57: 67-75 (2013)

[13] Sun Y, Bailey R. Improvement in tribocorrosion behavior of 304 stainless steel by surface mechanical attrition treatment. Surf Coat Technol 253: 284-291 (2014)

[14] Barcelos M A, Barcelos M V, de Sousa Araújo Filho J, Franco Jr A R, Vieira E A. Wear resistance of AISI 304 stainless steel submitted to low temperature plasma carburizing. REM Int Eng J 70(3): 293-298 (2017)

[15] Dong W P, Sullivan P J, Stout K J. Comprehensive study of parameters for characterising three-dimensional surface 
topography: IV: Parameters for characterising spatial and hybrid properties. Wear 178(1-2): 45-60 (1994)

[16] Dong W P, Sullivan P J, Stout K J. Comprehensive study of parameters for characterising three-dimensional surface topography: III: Parameters for characterising amplitude and some functional properties. Wear 178(1-2): 29-43 (1994)

[17] Dong W P, Sullivan P J, Stout K J. Comprehensive study of parameters for characterizing three-dimensional surface topography II: Statistical properties of parameter variation. Wear 167(1): 9-21 (1993)

[18] Dong W P, Stout K J. An integrated approach to the characterization of surface wear I: Qualitative characterization. Wear 181-183: 700-716 (1995)

[19] Raina A, Anand A. Influence of surface roughness and nanoparticles concentration on the friction and wear characteristics of PAO base oil. Mater Res Express 5(9): 095018 (2018)

[20] Lenart A, Pawlus P, Dzierwa A. The effect of steel disc surface texture in contact with ceramic ball on friction and wear in dry fretting. Surf Topogr Metrol Prop 6(3): 034004 (2018)

[21] Zhu S G, Huang P. Influence mechanism of morphological parameters on tribological behaviors based on bearing ratio curve. Tribol Int 109: 10-18 (2017)

[22] Prajapati D K, Tiwari M. 3D numerical wear model for determining the change in surface topography. Surf Topogr Metrol Prop 6(4): 045006 (2018)

[23] Clarke A, Evans H P, Snidle R W. Understanding micropitting in gears. Proc Inst Mech Eng Part C J Mech Eng Sci 230(7-8): 1276-1289 (2016)

[24] Clarke A, Weeks I J J, Snidle R W, Evans H P. Running-in and micropitting behaviour of steel surfaces under mixed lubrication conditions. Tribol Int 101: 59-68 (2016)

[25] Ghosh A, Sadeghi S. A novel approach to model effects of surface roughness parameters on wear. Wear 338-339: 7394 (2015)

[26] Mortazavi V, Khonsari M M. On the prediction of transient wear. J Tribol 138(4): 041604 (2016)

[27] Akbarzadeh S, Khonsari M M. On the optimization of running-in operating conditions in applications involving EHL line contact. Wear 303(1-2): 130-137 (2013)

[28] Sedlaček M, Podgornik B, Vižintin J. Correlation between standard roughness parameters skewness and kurtosis and tribological behaviour of contact surfaces. Tribol Int 48: 102-112 (2012)
[29] Deleanu L, Andrei G, Maftei L. Surface characterization of polymer composite using bearing area curve. In Proceedings of the ASME 2010 10th Biennial Conference on Engineering Systems Design and Analysis, Istanbul, Turkey, 2010.

[30] Khare N, Limaye P K, Singh K, Jadhav D T, Bute A, Kalel N. Experimental and theoretical analysis of Zircaloy-4 and AISI 304 stainless steel material pair in water sliding conditions. Adv Tribol 2018: 7575216 (2018)

[31] Zandrahimi M, Reza Bateni M, Poladi A, Szpunar J A. The formation of martensite during wear of AISI 304 stainless steel. Wear 263(1-6): 674-678 (2007)

[32] Bhushan B. Principles and Applications of Tribology. 2nd edn. Hoboken (UK): John Wiley \& Sons, 2013.

[33] Greenwood J A, Williamson J B P. Contact of nominally flat surfaces. Proc Roy Soc A 295(1442): 300-319 (1966)

[34] Prajapati D K, Tiwari M. Topography analysis of random anisotropic Gaussian rough surfaces. J Tribol 139(4): 041402 (2017)

[35] Pawar G, Pawlus P, Etsion I, Raeymaekers B. The effect of determining topography parameters on analyzing elastic contact between isotropic rough surfaces. J Tribol 135(1): 011401 (2013)

[36] Roy S, White D, Sundararajan S. Correlation between evolution of surface roughness parameters and micropitting of carburized steel under boundary lubrication condition. Surf Coat Technol 350: 445-452 (2018)

[37] Radhika N, Raghu R. Prediction of mechanical properties and modeling on sliding wear behavior of LM25/TiC composite using response surface methodology. Particul Sci Technol 36(1): 104-111 (2017)

[38] Cho M H, Bahadur S, Anderegg J W. Design of experiments approach to the study of tribological performance of $\mathrm{Cu}$ concentrate-filled PPS composites. Tribol Int 39(11): 14361446 (2006)

[39] Ilzarbe L, Álvarez M J, Viles E, Tanco M. Practical applications of design of experiments in the field of engineering: A bibliographical review. Qual Reliab Eng Int 24(4): 417428 (2008)

[40] Montgomery D C. Design and Analysis of Experiments. 7th edn. New Jersey (USA): John Wiley \& Sons, 2009.

[41] ISO. ISO 25178-2: 2012 Geometrical product specifications (GPS)—surface texture: Areal-Part 2: Terms, definitions and surface texture parameters. International Organization for Standardization, 2012.

[42] Thomas T R. Rough Surfaces. 2nd edn. London (UK): Imperial College Press, 1999. 


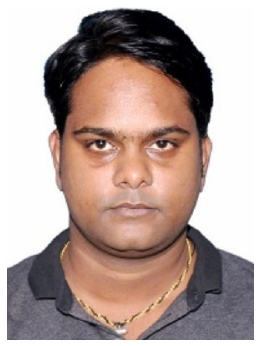

Deepak K. PRAJAPATI. He received his master degree in applied mechanics in 2014 from Motilal Nehru National Institute of Technology, India. After then, he was a Ph.D. student in Department of Me-

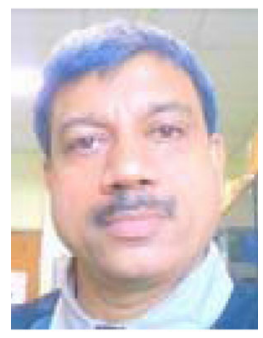

Mayank TIWARI. He received his Ph.D. degree in Department of Mechanical Engineering from IIT, India, in 1998. He was postdoctorate fellow in The Ohio State University, USA, in 1999-2001. He has twelve-year experience in chanical Engineering at Indian Institute of Technology (IIT), India. He has recently completed his Ph.D. degree in tribology under design stream. His research interests include multi-scale characterization of rough surfaces, analysis of mixed-EHL and EHL contacts, and surface contact fatigue.

general electric and aviation. In 2013, he joined Department of Mechanical Engineering at IIT, India. His current position is an associate professor and he is in charge of tribology laboratory at IIT. His research areas cover the design of gearboxes, rolling element bearings, $\mathrm{NVH}$, vacuum tribology, and rotor dynamics. 